University of Nebraska - Lincoln

DigitalCommons@University of Nebraska - Lincoln

\title{
On the discrepancy between eddy covariance and lysimetry-based surface flux measurements under strongly advective conditions
}

\author{
Joseph G. Alfieri \\ USDA-ARS, joe.alfieri@ars.usda.gov \\ William P. Kustas \\ USDA-ARS \\ John H. Prueger \\ USDA-ARS \\ Lawrence E. Hipps \\ Utah State University \\ Steven R. Evett \\ USDA-ARS
}

See next page for additional authors

Follow this and additional works at: https://digitalcommons.unl.edu/usdaarsfacpub

Alfieri, Joseph G.; Kustas, William P.; Prueger, John H.; Hipps, Lawrence E.; Evett, Steven R.; Basara, Jeffrey B.; Neale, Christopher M.U.; French, Andrew N.; Colaizzi, Paul; Agam, Nurit; Cosh, Michael H.; Chavez, José L.; and Howell, Terry A., "On the discrepancy between eddy covariance and lysimetry-based surface flux measurements under strongly advective conditions" (2012). Publications from USDA-ARS / UNL Faculty. 1140.

https://digitalcommons.unl.edu/usdaarsfacpub/1140

This Article is brought to you for free and open access by the U.S. Department of Agriculture: Agricultural Research Service, Lincoln, Nebraska at DigitalCommons@University of Nebraska - Lincoln. It has been accepted for inclusion in Publications from USDA-ARS / UNL Faculty by an authorized administrator of DigitalCommons@University of Nebraska - Lincoln. 


\section{Authors}

Joseph G. Alfieri, William P. Kustas, John H. Prueger, Lawrence E. Hipps, Steven R. Evett, Jeffrey B. Basara, Christopher M.U. Neale, Andrew N. French, Paul Colaizzi, Nurit Agam, Michael H. Cosh, José L. Chavez, and Terry A. Howell 


\title{
On the discrepancy between eddy covariance and lysimetry-based surface flux measurements under strongly advective conditions ${ }^{\text {is }}$
}

\author{
Joseph G. Alfieri ${ }^{\mathrm{a}, *}$, William P. Kustas ${ }^{\mathrm{a}}$, John H. Prueger ${ }^{\mathrm{b}}$, Lawrence E. Hipps ${ }^{\mathrm{c}}$, Steven R. Evett ${ }^{\mathrm{d}}$, \\ Jeffrey B. Basara ${ }^{e}$, Christopher M.U. Neale ${ }^{f}$, Andrew N. French ${ }^{g}$, Paul Colaizzi ${ }^{d}$, Nurit Agam ${ }^{\mathrm{h}}$, \\ Michael H. Cosh ${ }^{\text {, }}$, José L. Chavez ${ }^{i}$, Terry A. Howell ${ }^{\mathrm{d}}$ \\ ${ }^{a}$ USDA-ARS Hydrology and Remote Sensing Laboratory, Beltsville, MD 20705, United States \\ ${ }^{\mathrm{b}}$ USDA-ARS National Laboratory for Agriculture and the Environment, Ames, IA 50011, United States

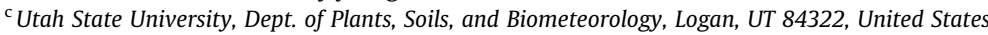 \\ ${ }^{\mathrm{d}}$ USDA-ARS Conversation and Production Research Laboratory, Bushland, TX 79012, United States \\ e Oklahoma Climatological Survey, University of Oklahoma, 120 David L. Boren Blvd., Norman, OK 73072, United States \\ ${ }^{\mathrm{f}}$ Utah State University, Dept. of Civil and Environmental Engineering, 4105 Old Main Hill, Logan, UT 84322, United States \\ ${ }^{9}$ USDA-ARS Arid-Land Agricultural Research Center, Maricopa, AZ 85238, United States \\ ${ }^{\mathrm{h}}$ Gilat Research Center, Agricultural Research Organization, Rural Delivery Negev, 85280, Israel \\ ${ }^{\mathrm{i}}$ Colorado State University, Dept. of Civil and Environmental Engineering, Fort Collins, CO 80523, United States
}

\section{A R T I C L E I N F O}

\section{Article history:}

Available online 17 July 2012

\section{Keywords:}

Surface energy flux

Evapotranspiration

Advection

Eddy covariance

Lysimetry

Surface heterogeneity

\begin{abstract}
A B S T R A C T
Discrepancies can arise among surface flux measurements collected using disparate techniques due to differences in both the instrumentation and theoretical underpinnings of the different measurement methods. Using data collected primarily within a pair of irrigated cotton fields as a part of the 2008 Bushland Evapotranspiration and Remote Sensing Experiment (BEAREX08), flux measurements collected with two commonly-used methods, eddy covariance (EC) and lysimetry (LY), were compared and substantial differences were found. Daytime mean differences in the flux measurements from the two techniques could be in excess of $200 \mathrm{~W} \mathrm{~m}^{-2}$ under strongly advective conditions. Three causes for this disparity were found: (i) the failure of the eddy covariance systems to fully balance the surface energy budget, (ii) flux divergence due to the local advection of warm, dry air over the irrigated cotton fields, and (iii) the failure of lysimeters to accurately represent the surface properties of the cotton fields as a whole. Regardless of the underlying cause, the discrepancy among the flux measurements underscores the difficulty in collecting these measurements under strongly advective conditions. It also raises awareness of the uncertainty associated with in situ micrometeorological measurements and the need for caution when using such data for model validation or as observational evidence to definitively support or refute scientific hypotheses.
\end{abstract}

Published by Elsevier Ltd.

\footnotetext{
is The US Department of Agriculture (USDA) prohibits discrimination in all its programs and activities on the basis of race, color, national origin, age, disability, and where applicable, sex, marital status, familial status, parental status, religion, sexual orientation, genetic information, political beliefs, reprisal, or because all or part of an individual's income is derived from any public assistance program. (Not all prohibited bases apply to all programs.) Persons with disabilities who require alternative means for communication of program information (Braille, large print, audiotape, etc.) should contact USDA's TARGET Center at (202) 720-2600 (voice and TDD). To file a complaint of discrimination, write to USDA, Director, Office of Civil Rights, 1400 Independence Avenue, S.W., Washington, DC 20250-9410, or call (800) 795-3272 (voice) or (202) 720-6382 (TDD). USDA is an equal opportunity provider and employer.

* Corresponding author. Address: USDA-ARS Hydrology and Remote Sensing Laboratory, Bldg 007, Rm 104, BARC-W, 10300 Baltimore Ave., Beltsville, MD 20705, United States. Tel.: +1 (301) 5045673.

E-mail address: joe.alfieri@ars.usda.gov (J.G. Alfieri).
}

\section{Introduction}

Satisfying the competing freshwater needs of the urban, industrial, and agricultural communities is already a difficult task in many parts of the world [1-3]. As pointed out by Vörösmarty et al. [4] and Zehnder et al. [5], water scarcity is a global issue with the demand for freshwater exceeding the supply in nearly 80 countries [6]. It has been estimated that one-third of the world's population living in regions as disparate as northern Africa, the Middle East, Australia, India and China suffer from severe water shortages [7-9] and it is projected that the percentage of the population that will be impacted by water scarcity will increase to $67 \%$ by 2050 [10].

Securing sufficient water resources is also of significant concern in the United States. This is particularly true in the western half of the country where meeting the current needs of the population is 
already problematic, freshwater resources are fully appropriated, and significant water shortages are anticipated in the coming years $[11,12]$. Cities such as Los Angeles, California and Denver, Colorado have long needed to access water well away from the municipalities in order to satisfy the demands of urban users, often at the expense of agricultural and rural water needs $[1,13,14]$. Similar issues can be found in the American Southwest, the fastest growing region in the United States, where water use has increased by $58 \%$ or $28.6 \mathrm{~km}^{3} \mathrm{yr}^{-1}$ since 1950 [15]. Limited water resources in the Southwest have necessitated the introduction of more robust crops that are better suited to the arid environment of the region [16]. In other parts of the western United States, such as the high plains of Kansas, where the economy is highly dependent on irrigated agriculture, the depletion of local groundwater resources presents a significant issue to water managers and policy makers seeking to ensure sufficient water supplies into the future [17].

The task of ensuring there is sufficient water to meet the needs of all end users is expected to become more difficult in the coming years as the demand for water increases with a growing population, evolving dietary preferences, and changing climate [18-20]. In order meet that demand, policy makers, water managers, and consumers must find ways to maximize the effective use of limited freshwater resources. Since irrigation is the largest user of freshwater resources representing between $70 \%$ and $80 \%$ of total freshwater withdrawals and $90 \%$ of consumptive water use globally during the last century [21,22], it has become a critical focus of water conservation efforts [23-26]. Similarly, according to data provided as a part of the most recent governmental assessment of water use [27], irrigation is the largest user of water in the western United States and largest consumptive user of freshwater resources nationally.

Improving the effectiveness of irrigation requires accurate estimates of both the current water needs of the crops and the evaporative losses from the fields. Increasingly, these estimates are obtained using remote sensing-based models [28-30], particularly when ET estimates are needed on a regional scale. These remote sensing-based methods are typically validated and calibrated using in situ measurements. Although there are numerous techniques for measuring evapotranspiration (ET), eddy covariance (EC) and lysimetry (LY) are two of the most prevalent. The eddy covariance method determines the moisture flux as a function of the covariance between vertical wind speed and water vapor density while LY measures ET as a function of the change in mass of a contained volume of soil over time. Each of these methods has its own advantages and disadvantages related to its theoretical underpinning and in-field application [31]. For example, while LY is a direct estimate of ET, the limited measurement footprint may not be representative of the surrounding area. While EC measurements are integrated over a larger source area, spatial variability in atmospheric and surface conditions can adversely impact the quality of those measurements as well. Understanding the effects of the measurement technique on the accuracy and representativeness of the measurements from both techniques is critical in order to characterize and account for the uncertainties in the measurements when using them for subsequent analyses such as the development and validation of remote sensing-based models.

In order to discern the theoretical and practical reasons that would cause EC and LY-based surface flux measurements to differ, data collected over a pair of irrigated cotton fields as a part of the 2008 Bushland Evapotranspiration and Agricultural Remote Sensing Experiment (BEAREX08; see ref. [85]) were compared. The field campaign was carried out under hot, dry, and windy conditions during BEAREX08, the mean daytime air temperature, water vapor pressure deficit, and wind speed were $30^{\circ} \mathrm{C}, 2.5 \mathrm{kPa}, 4.5 \mathrm{~m} \mathrm{~s}^{-1}$, respectively - that typify not only the panhandle of Texas, but many other arid and semi-arid regions as well. As a result, this study provided a unique opportunity to evaluate EC and LY-based measurements under strongly advective conditions.

The following section of the paper provides an overview of the field site and the measurements used in this study. It also provides a description of several key analysis techniques used herein. Section 3 of the paper presents and discusses the results of this study. Finally, Section 4 of the paper presents the conclusions that can be drawn from this study along with recommendations for the use of EC and LY-based measurements collected in similar environments.

\section{Methods}

\subsection{Site description}

The 2008 Bushland Evapotranspiration and Agricultural Remote Sensing Experiment was conducted from June through August 2008 at the USDA-ARS Conservation and Production Research Laboratory (CPRL) near Bushland, Texas $\left(35.183^{\circ} \mathrm{N}, 102.100^{\circ} \mathrm{W}\right.$, $1170 \mathrm{~m}$, asl). As a part of the field campaign, surface energy fluxes were measured over a pair of adjacent, irrigated cotton fields using both EC micrometeorological stations and large monolithic weighing lysimeters. A lysimeter was positioned near the center of each field along with a co-located EC station positioned approximately $15 \mathrm{~m}$ northeast of the lysimeter; a second EC station was located in the northeast quadrant of the field (Fig. 1). Both of the fields measured approximately $220 \mathrm{~m} \times 220 \mathrm{~m}$ and had an area of $4.7 \mathrm{ha}$. The key difference between the fields was the orientation of the crop rows; the rows in the Northeast Field (NEF) were oriented north-south while the rows of cotton in the Southeast Field (SEF) were oriented west-east. In NEF, the EC system in the northeast corner of the field will be referred to as Site 1 while the station co-located with the lysimeter in the same field will be referred to

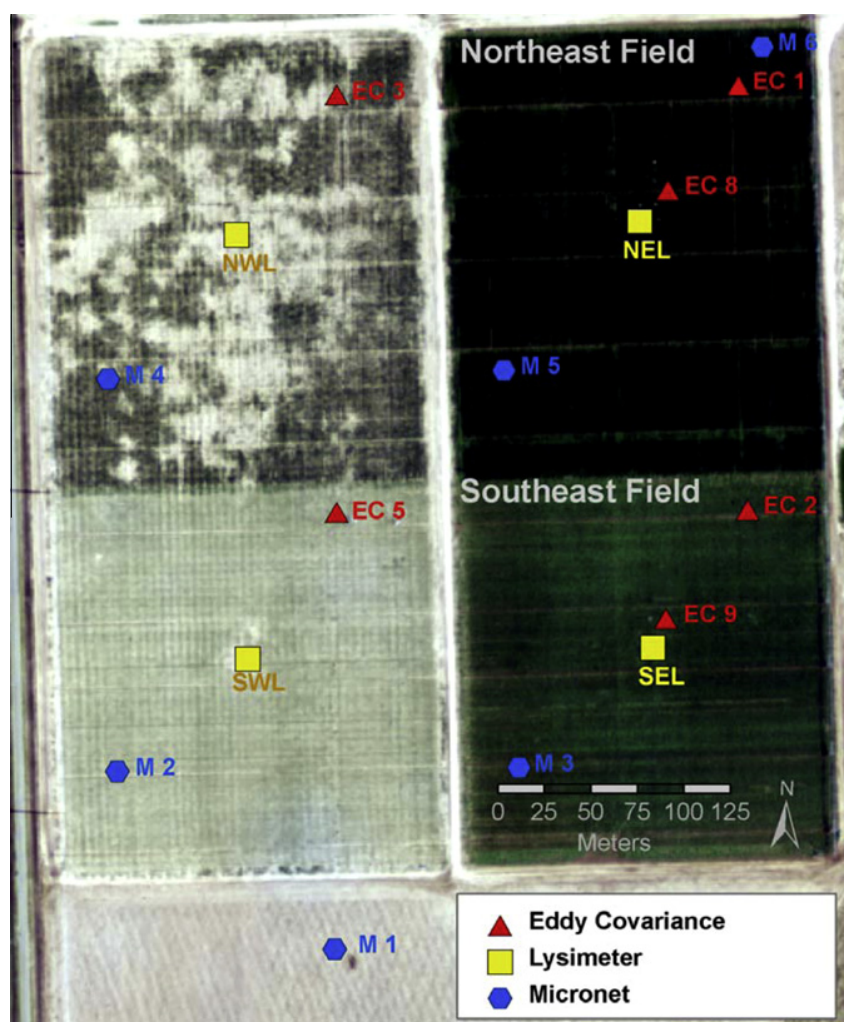

Fig. 1. Schematic showing the location of the eddy covariance stations, lysimeters, and Micronet Stations in each field. 

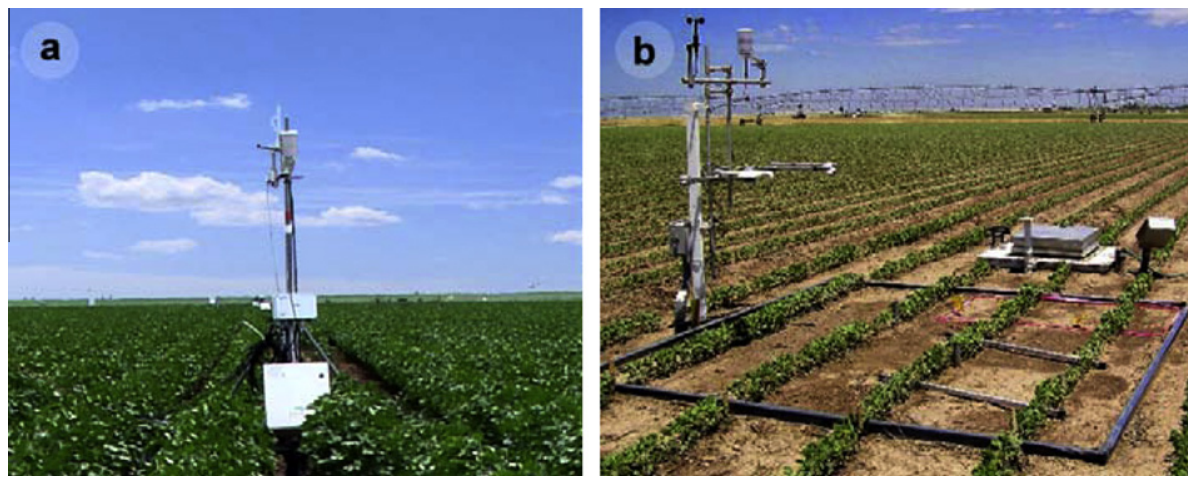

Fig. 2. The eddy covariance system at Site 1 (a) and the lysimeter in the Northeast Field (b) are shown.

as Site 8 . In SEF, the EC system in the northeast corner of the field will be referred to as Site 2 while the station co-located with the lysimeter will be referred to as Site 9 . The lysimeter in NEF will be referred to as NEL while the one in SEF will be referred to as SEL.

\subsection{Measurements}

\subsubsection{Eddy covariance}

Each of the EC micrometeorological systems (Fig. 2a) was equipped with a sonic anemometer (CSAT- $3,{ }^{1}$ Campbell Scientific Inc., Logan, Utah) to measure the orthogonal wind velocity components and an open-path infrared gas analyzer (LI-7500, Li-COR Biosciences, Lincoln, Nebraska) to measure both water vapor and carbon dioxide concentration. At Site 1 and 2, these instruments were mounted facing due south at a nominal height of $2.25 \mathrm{~m}$ agl. At Site 8 and 9, they were mounted facing southwest $\left(225^{\circ}\right)$ at a height of $2.5 \mathrm{~m}$ agl. In all cases, these measurements were collected at a frequency of $20 \mathrm{~Hz}$. Additional instruments at Sites 1 and Site 2 included a combined humidity and temperature sensor (HMP45C, Vaisala, Helsinki, Finland), pressure sensor (CS106, Campbell Scientific, Logan, Utah), a four-component net radiometer (CNR-1, Kipp and Zonen, Delft, The Netherlands), three soil heat flux plates (HFT-3, Radiation Energy Balance Systems, Bellevue, Washington) buried at a depth of $8 \mathrm{~cm}$ paired with soil thermocouples (Omega Engineering, Inc. Stamford, Connecticut) and soil moisture probes (HydraProbe, Stevens Water Monitoring Systems, Portland Oregon). The soil moisture sensors were buried horizontally at a depth of $5 \mathrm{~cm}$. Independent measurements of net radiation $\left(R_{n}\right)$ and soil heat flux $(G)$ were not collected at Sites 8 and 9; instead, the nonturbulent flux measurements collected at the nearby lysimeters were used.

The flux data were post-processed using the full complement of standard corrections and adjustments. Nonphysical values and outliers were first removed without replacement from the high frequency $(20 \mathrm{~Hz})$ data using a moving window algorithm based on the method outlined by Goring and Nikora [32]. Next, a twodimensional rotation was applied to the wind velocity components $(u, v$, and $w)$ so that the coordinate system was aligned into the prevailing wind direction $[33,34]$. Third, the data were corrected for sensor displacement and frequency response attenuation $[35,36]$. Finally, 1 -h block average turbulent fluxes were calculated. These fluxes were then corrected for the effects of heat and water vapor density [37,38]. The air temperature from the sonic anemometer was also corrected for humidity effects according to Liu et al. [39]. Based on the analysis of Alfieri et al. [40], the resulting flux measurements have an uncertainty of $13 \mathrm{~W} \mathrm{~m}^{-2}$ and $27 \mathrm{~W} \mathrm{~m}^{-2}$, respectively, for the sensible $(H)$ and latent $(\lambda E)$ heat

\footnotetext{
${ }^{1}$ Company and trade names are given for the benefit of the reader only and do not imply any endorsement or recommendation by US Department of Agriculture.
}

flux. Although the instruments at the lysimeter sites were not included in the evaluation, a similar analysis conducted on the measurements of net radiation $\left(R_{n}\right)$ using the other four-component net radiometers used during the field campaign indicated that those measurements have an uncertainty of approximately $12 \mathrm{~W} \mathrm{~m}^{-2}$; this is in agreement with the uncertainty estimates from several other recent studies [41-43].

The soil moisture measurements from the HydraProbe sensors were corrected using a two-step process that first corrected the estimated permittivity and then applied the soil-specific calibration (see also ref. [86]). These measurements were then used to correct $G$ for heat storage in the overlying soil layer.

The data used in this study was collected during the period from 4 July [Day of Year (DOY) 186] through 7 August (DOY 220) excluding those days when there was a precipitation or irrigation event. During this study period, the cotton fields transitioned from essentially bare soil conditions to fully vegetated.

\subsubsection{Lysimeters}

A large weighing lysimeter (Fig. 2b) was located in the center of each of the irrigated cotton fields. While a detailed description of the lysimeters can be found in Marek et al. [44] and Howell et al. [45], a brief description is provided here. Each weighing lysimeter measured $3 \mathrm{~m} \times 3 \mathrm{~m}$ and contained a $2.4 \mathrm{~m}$ soil monolith of Pullman silty clay loam, the same soil as in the larger fields [46]. The weighing system consisted of a counter-balanced multi-lever scale and a load cell read by a high-resolution datalogger. The lysimeters were calibrated prior to the field campaign using masses traceable to NIST standards and found to be accurate to within $0.04 \mathrm{~mm} \mathrm{~h}^{-1}$, or equivalently, $27 \mathrm{~W} \mathrm{~m}^{-2}$.

The lysimeters were managed in order to replicate conditions in the surrounding field as closely as possible. The lysimeters were hand-seeded on the same day, 21 May (DOY 141), the fields were planted. Then, after emergence, the cotton plants in the lysimeters were thinned to match the density $\left(16\right.$ plants $\mathrm{m}^{-2}$ ) of the surrounding fields. Additionally, irrigation of the plants within the lysimeters was identical to that of the fields. Nonetheless, as is discussed by Evett et al. [85], the cotton plants inside the lysimeter were larger and tended to grow more rapidly than those in the surrounding field; this is particularly true of NEL.

Additionally, each lysimeter site was equipped with a fourcomponent net radiometer (CNR-1, Kipp and Zonen, Delft, The Netherlands), four soil heat flux plates (HFT-3, Radiation Energy Balance Systems, Bellevue, Washington), and four pairs of soil thermocouples (TMTSS-125G, Omega Engineering Inc., Stamford, CT). The soil sensors were spaced at $15 \mathrm{~cm}$ intervals along a transect beginning in the row and extending perpendicular to the row direction. The measurements were used to determine both $R_{n}$ and $G$ at each of the lysimeters. Finally, soil moisture profiles to a depth of approximately $2 \mathrm{~m}$ were measured both within the 
lysimeters and at four adjacent locations within each field using a neutron probe (model 503DR1.5, Campbell Pacific Nuclear, Concord, California). These measurements, which are described in detail in Evett et al. [85], were collected on a weekly basis through the course of the field campaign.

\subsubsection{Additional data}

In addition to the flux measurements described above, a number of ancillary datasets were used in this analysis. The first of these are leaf area index (LAI) estimates derived from airborne imagery collected using the Utah State University multispectral imaging system $[47,48]$. The imaging system consists of three digital cameras (Megaplus 4.2i, Eastman Kodak, Rochester, NY) and a thermal-infrared scanner sensitive to electromagnetic energy in the $8-12 \mu \mathrm{m}$ portion of the spectrum. Each camera is equipped with an interference filter to filter for the green $(545-560 \mathrm{~nm})$, red $(665-680 \mathrm{~nm})$, or near-infrared $(795-809 \mathrm{~nm})$ portion of the electromagnetic spectrum. Six images were collected on 26 June (DOY 178) 12 July (DOY 194), 20 July (DOY 202), 28 July (DOY 210), 5 August (DOY 218), and 13 August (DOY 216). The 1-m resolution LAI maps of the cotton fields were generated using the best-fit sigmoidal relationship between the in situ LAI measurements collected via destructive sampling at six locations in the cotton fields and the normalized difference vegetation index (NDVI) calculated using the airborne multispectral measurements. Although the resulting fit did not match the LAI measurements from either of the individual fields perfectly, combining the LAI measurements from both fields produced a much better overall fit. Moreover, since the focus here is on relative differences, the uncertainty in the absolute value of LAI has minimal impact on the analysis.

Additional meteorological measurements were collected at six locations in and around the irrigated cotton fields (Fig. 1) using Micronet stations [49,50]. The measurements included air temperature, relative humidity, pressure, wind speed, wind direction, and precipitation. All of the measurements were collected at a nominal height of $2 \mathrm{~m}$ agl using a multi-component weather sensor (WXT150, Vaisala). The measurements, with the exception of precipitation, were measured once per minute and aggregated to an hourly time step.

A third auxiliary dataset used in this study, which is described in detail by Agam et al. [86], was the soil heat flux measurements collected at a pair of intensive study locations adjacent to the lysimeter in each field. Ten soil heat flux plates (HFT-3, Radiation Energy Balance Systems) were deployed at each intensive study location along with copper-constantan thermocouples. The thermocouples were deployed at depths of $2 \mathrm{~cm}$ and $6 \mathrm{~cm}$ while the soil heat flux plates were buried at a depth of $8 \mathrm{~cm}$. The soil moisture data needed to correct the heat flux measurements to the surface was collected using dielectric permittivity sensors (Hydra Probe, Stevens Water Monitoring Systems, Portland Oregon) installed horizontally at a depth of $5 \mathrm{~cm}$. There were six of these probes in NEF and five in SEF. The instruments were deployed along a pair of $76 \mathrm{~cm}$ inter-row transects with a horizontal separation of approximately $15 \mathrm{~cm}$. The soil moisture measurements were corrected using the same two-step process as described above.

Finally near-surface soil moisture $(\theta)$ was measured using a network of 10 soil moisture sensors (Hydra Probe, Stevens Water Monitoring Systems) distributed along a pair of transects extending diagonally from the opposing corners of the two fields (see Cosh et al., 2012). Five sensors were located within NEF and five sensors were located in SEF. All of the soil moisture probes were inserted horizontally and buried at a depth of $5 \mathrm{~cm}$. The measurements from each sensor were stored as 30-min means and corrected as described above.

\subsection{Analysis methods}

\subsubsection{Spatial analysis of leaf area index and soil moisture content}

The spatial variability of both LAI and $\theta$ were analyzed using variography, a well-established spatial statistical method, following the procedure described by Alfieri et al. [51] who used variography to quantify the spatial variability in airborne flux measurements. Briefly, by assuming LAI and $\theta$ each exhibit second-order stationarity, i.e. the correlation between the measurements at any two locations is a function of the distance between them, the semivariance at each location can be characterized according to

$\gamma(h)=\tau^{2}+\sigma^{2}[1-C(h)]$

where $\gamma$ is the semivariance, $h$ is the separation distance between locations, $\tau^{2}$ is the non-spatial component of the variance, $\sigma^{2}$ is the spatial component of the variance and $C(h)$ is a valid covariance function [52]. A valid covariance function is positive definite and fulfills the assumption that proximal locations are more strongly related than distal ones [53].

Because the full $1-\mathrm{m}$ resolution dataset derived from the airborne imagery would have been computationally impractical, a subsample of approximately 500 locations was selected for the variographic analysis of LAI. The points were selected by using a set of nested grids with resolutions of $20 \mathrm{~m}, 10 \mathrm{~m}, 5 \mathrm{~m}$, and $1 \mathrm{~m}$, respectively (Fig. 3 ). In order to ensure that the subsample was representative of the field as a whole, summary statistics calculated using the subsample of LAI measurements were compared to statistics calculated using the LAI measurements for the entire field. Close agreement was found for both NEF and SEF.

In the case of $\theta$, the five measurements from the portion of the soil moisture network located in each of the fields were analyzed separately. The variographic analysis was used to determine both the spatial and the total variability of $\theta$ in each of the fields. Both are characterized in terms of the variance among the measurements.

\subsubsection{Flux footprint}

The flux footprint, which was first introduced by Pasquill and Smith [54], defines both the source area and the relative contribution of each upwind surface element to the measured flux [55]. In other terms, the flux footprint defines the "field of view" of the turbulent flux measurements. As discussed by Schmid [56] among others, the relationship defining the measured flux at some location, $(x, y)$, can be expressed in its most generalized form as

$F_{m}(x, y)=\iint F\left(x^{\prime}, y^{\prime}\right) \Phi\left(x-x^{\prime}, y-y^{\prime}\right) \partial x^{\prime} \partial y^{\prime}$

where $F_{m}(x, y)$ is the measured flux, $F\left(x^{\prime}, y^{\prime}\right)$ is the flux at the point located at $\left(x^{\prime}, y^{\prime}\right)$ and $\Phi\left(x-x^{\prime}, y-y^{\prime}\right)$ is the footprint or weighting function that defines the sensitivity of the measured flux to the location $\left(x^{\prime}, y^{\prime}\right)$.

In this study, the analytical footprint model proposed by Hsieh et al. [57] was used in conjunction with a simple Gaussian plume dispersion model to identify the source area contributing $90 \%$ of the measured flux for each hourly period during the study. Since the size and orientation of the footprint changes as a function wind speed and direction, atmospheric stability, and surface roughness $[55,56,58,59]$, the flux footprint was calculated for each hour during the study period and the resulting data were averaged to produce a composite footprint representing the typical source area.

\subsubsection{Estimation of flux divergence}

Advection occurs when air in equilibrium with one surface is transported horizontally across a second surface with differing characteristics, such as surface roughness, temperature, or moisture availability [60]. When advection occurs, it can significantly 


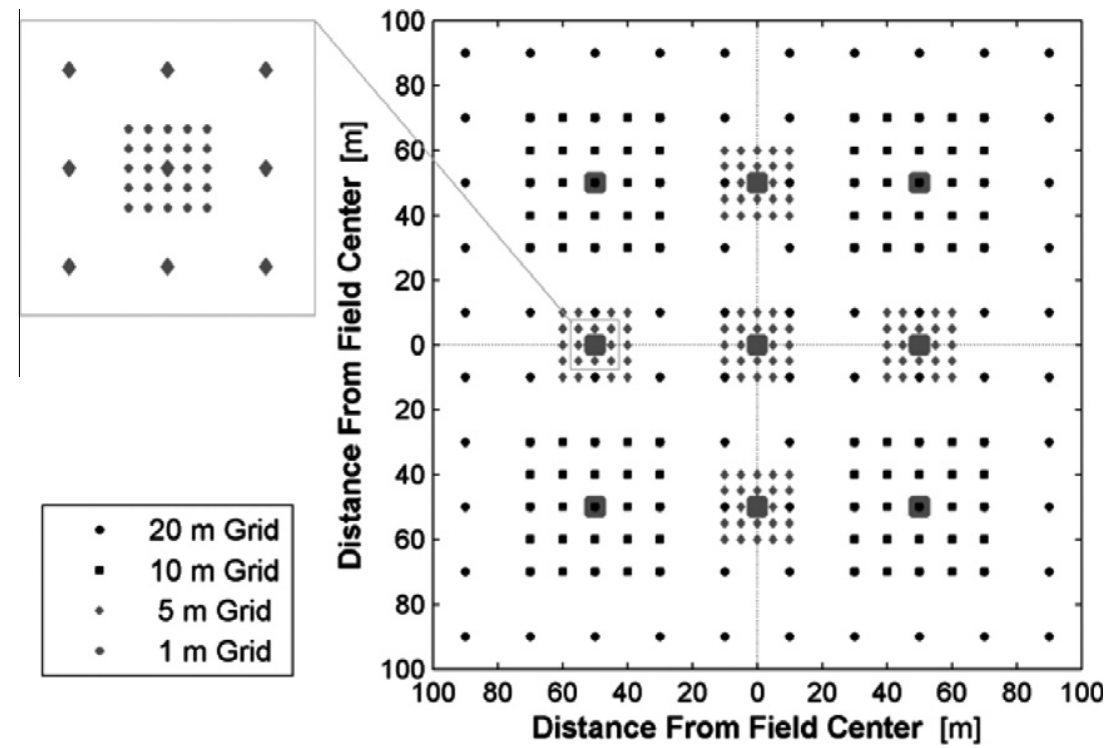

Fig. 3. The locations of the subsampled LAI measurements selected by the four nested grids for use in the spatial analysis of LAI.

alter the exchange of mass, energy, and momentum between the land surface and the atmosphere. For example, when warm dry air is transported across a cool moister surface, evaporative processes can be substantially enhanced because the advected air supplies both additional energy to drive evaporation and increases the atmospheric demand $[61,62]$. This effect is particularly important over croplands in arid and semi-arid regions, such as the Texas High Plains, where irrigated fields are interspersed among dryland areas [60-67].

In order to ascertain the effects of advection on the measurements of the turbulent fluxes by the EC systems, the simple method for estimating the flux divergence described by Prueger et al. [61], among others, was used. Following this method, the advective enhancement of $\lambda E$ is estimated from the flux divergence of $H$ and is calculated as:

$-\lambda E_{a d v}=\Delta H=H_{s}-H_{m}=\rho c_{p} \int_{z_{0}}^{z_{m}} U(z) \frac{\partial T(z)}{\partial x} \partial z$

where $\lambda E_{a d v}$ is the advective contribution to $\lambda E, \Delta H$ is the flux divergence of $H, H_{s}$ is $H$ at the surface, $H_{m}$ is $H$ at the measurement height, $\rho$ is the density of air, $c_{p}$ is the specific heat, $z_{m}$ is the measurement height, $z_{0}$ is the roughness length, $U$ is wind speed, $T$ is air temperature, $z$ is the height above the surface, and $x$ is the downwind distance from the edge of the irrigated fields. Due to limited data, implementing even this approximate method for estimating $\lambda E_{a d v}$ required a number of assumptions. For example, because vertical profiles of $U$ and $T$ were not measured at multiple locations in the NEF and SEF, it was necessary to estimate them using the stability-corrected logarithmic profiles predicted by Monin-Obukhov similarity theory [68].

More notably, quite often, there were insufficient measurements to fit $T$ to the expected power law relationship with $x$ [6971]. In an effort to overcome this, $\lambda E_{a d v}$ was calculated indirectly by first solving the above integral while assuming that that $T$ decreased linearly with $x$. The resulting estimate of $\lambda E_{a d v}$ was then adjusting to approximate the corresponding $\lambda E_{a d v}$ calculated using a power law relationship for $\frac{\partial T}{\partial x}$. (The estimate of $\frac{\partial T}{\partial x}$ assuming a power law-based relationship between $T$ and $x$ of will be referred to as $P$ hereafter while the estimate of $\frac{\partial T}{\partial x}$ assuming a linear horizontal temperature profile will be referred to as $M$; similarly, $\lambda E_{a d v}$ using $P$ and the estimate using $M$ will be referred to as $\lambda E_{P}$ and $\lambda E_{M}$, respectively.) The adjustment was conducted by multiplying $\lambda E_{M}$ and the appropriate value taken from an empirical relationship describing how $\lambda E_{P}$ and $\lambda E_{M}\left(\lambda E_{P: M}\right)$ varies with $x$. This approach is built on the premise that $\lambda E_{P: M}$ closely approximates the ratio of $P$ and $M$, an assumption that is reasonable when

$\overline{U(z)} \bar{P} \overline{P(z)^{z}} \gg \operatorname{Cov}(U(z), P(z))$

$\overline{U(z)^{z}} \overline{M(z)^{z}} \gg \operatorname{Cov}(U(z), M(z))$

where $P(z)$ is the vertical profile of $P, M(z)$ is the vertical profile in $M$, and overbar- $z\left({ }^{z}\right)$ denotes the mean with respect to height.

The empirical relationship describing how $\lambda E_{P: M}$ changes with $x$ was developed using 31 hourly measurements collected during daytime periods when the wind direction was nearly due south $\left(180^{\circ} \pm 5^{\circ}\right)$ and the Micronet data could be used to fit the horizontal temperature profile across the irrigated cotton fields. For each of these periods, the vertical wind speed profiles for the four EC systems in NEF and SEF were calculated using the local measurements of $U$ and assuming a logarithmic relationship between $U$ and $z$. Similarly, the vertical profiles of $T$ at Micronet stations 1, 3, 5, and 6, were calculated based on the local measurements of $\mathrm{T}$ and assuming a logarithmic relationship between $T$ and $z$. For the Micronet stations located within the two irrigated cotton fields, the characteristic temperature scale $(T *)$ was derived from data collected at the nearest EC system within NEF or SEF. In the case of the Micronet station located upwind of the cotton fields, Micronet $1, T *$ were derived from the data collected at EC Site 3, which was located in the adjacent field and was assumed to be representative of the surrounding region. The vertical temperature profiles were then used to determine the best-fit power law and linear relationships describing $T$ as a function of $x$ for a range of heights from $z_{0}$ to $z_{m}$ at $0.01 \mathrm{~m}$ increments. Using these best-fit relationships, $\mathrm{P}$ and $\mathrm{M}$ were determined for each of the EC systems based on the EC system's downwind distance from the southern edge of SEF using the appropriate best-fit relationship. Next, both $\lambda E_{P}$ and $\lambda E_{M}$ were calculated by numerically integrating equation (3). Finally, a random selection of 25 hourly periods were then used to derive the empirical relationship between $\lambda E_{P: M}$ and $x$. The remaining periods were used to evaluate the uncertainty associated with the estimates of $\lambda E_{a d v}$ using the empirical relation; these estimates will be referred to $\lambda E_{a d v}$. 


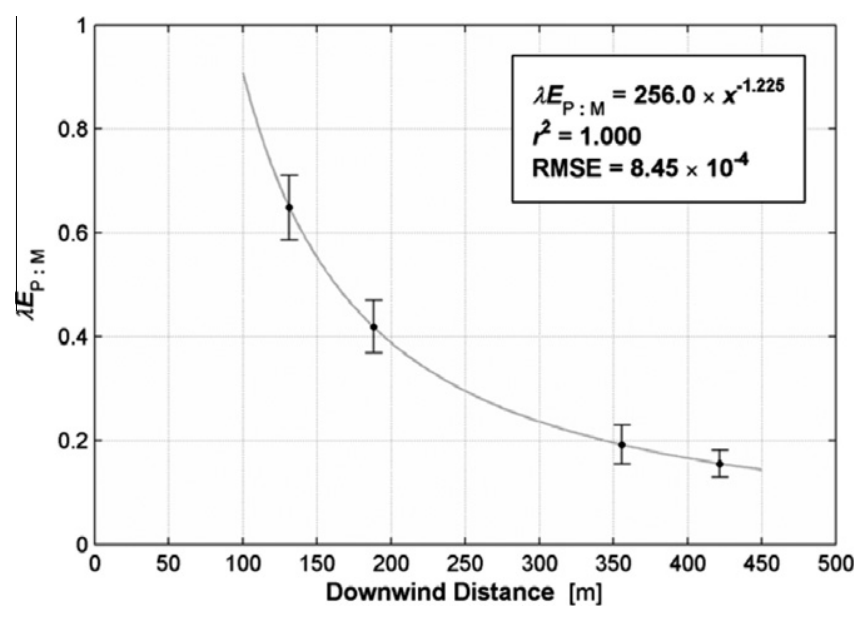

Fig. 4. The empirically-derived function relating the ratio of advective contributions to the latent heat flux calculated using a power law-based or linear horizontal temperature profile to downwind distance. The error bars represent the standard deviation at the location of the eddy covariance systems.

As can be seen in Fig. 4, which shows the mean $\lambda E_{P: M}$ for EC system as a function of it downwind location, $\lambda E_{P: M}$ has a well-defined relationship with $x$. The coefficient of determination $\left(r^{2}\right)$ was very near unity and the root mean square error (RMSE) of the best-fit line is $8.45 \times 10^{-4}$. This, along with the small values of Cov $(U(z), P(z))$ and $\operatorname{Cov}(U(z), M(z))$ compared to $\overline{U(z)^{z}} \overline{P(z)^{z}}$ and $\overline{U(z)^{z}} \overline{M(z)^{z}}$, further supports in the utility of this approach. The mean $\operatorname{Cov}(U(z), P(z))$ was $2.10 \times 10^{-4}{ }^{\circ} \mathrm{C} \mathrm{s}^{-1}$ while $\overline{U(z)^{z}} \overline{P(z)^{z}}$ averaged $1.09 \times 10^{-2}{ }^{\circ} \mathrm{C} \mathrm{s}^{-1}$. Similarly, the mean $\operatorname{Cov}(U(z), M(z))$, which was $1.97 \times 10^{-4}{ }^{\circ} \mathrm{C} \mathrm{s}^{-1}$, is two orders of magnitude smaller than the mean $\overline{U(z)^{z}} \overline{M(z)^{z}}$, which was $3.10 \times 10^{-2}{ }^{\circ} \mathrm{C} \mathrm{s}^{-1}$. A comparison of the calculated $\lambda E_{P}$ and $\lambda E_{a d v}$ showed good agreement between the values. The mean absolute difference (MAD) among the estimates averaged $2 \mathrm{~W} \mathrm{~m}^{-2}, 4 \mathrm{~W} \mathrm{~m}^{-2}, 3 \mathrm{~W} \mathrm{~m}^{-2}$, and $7 \mathrm{~W} \mathrm{~m}^{-2}$, respectively, for EC systems 1, 2, 8, and 9 during the six test periods. This corresponds to an uncertainty in $\lambda E_{a d v}$ of between $12 \%$ and $18 \%$.

\section{Results and discussion}

\subsection{Differences in the non-turbulent fluxes}

The mean difference (MD) between the measurements of $R_{n}$ at Site 1 and NEL $\left(\mathrm{MD}_{1, N}\right)^{2}$ was $42 \mathrm{~W} \mathrm{~m}^{-2}$ during the day (defined here as the period from 0900 to 1900 CST) with the measurements at Site 1 exceeding those at NEL. The mean absolute difference (MAD) of the $R_{n}$ measurements collected in NEF was also $42 \mathrm{~W} \mathrm{~m}^{-2}$. Since the differences were too large to have resulted from random error, an additional analysis of the radiation budget was conducted. By comparing the incident shortwave (solar) radiation $(K \downarrow)$ and longwave radiation $(L \downarrow)$ measurements collected during BEAREX08 in NEF and SEF, as well as the two adjacent fields immediately west, it was found that the instrument at Site 1 tended to provided the lowest measurements of both $K \downarrow$ an $L \downarrow$ while the net radiometer located with the lysimeter in NEF typically provided the highest measurement of $K \downarrow$ and always provided the highest measurement of $L \downarrow$. The overall effect of these tendencies was that the sum of $K \downarrow$ and $L \downarrow$ was consis-

\footnotetext{
${ }^{2}$ For this and other calculated quantities, the first subscript refers to the location of the minuend measurements while the second subscript refers to the location of the subtrahend measurements. In this case, the subscripts indicate that the measurements at the northeast lysimeter are being subtracted from the measurements at Site 1. Mathematically, $\mathrm{MD}_{1, \mathrm{~N}}$ can be expressed as: $\mathrm{MD}_{1, N}=\frac{1}{N} \sum_{1}^{N}\left(R_{n}\right.$ at Site $1 \mathrm{NE}-$ $R_{n}$ at NEL)
}

tently $36 \mathrm{~W} \mathrm{~m}^{-2}$ lower at Site 1 than at NEL. In turn, the daytime $R_{n}$ at Site 1 was also $36 \mathrm{~W} \mathrm{~m}^{-2}$ lower than at NEL. The effects of the bias in the measurements of $K \downarrow$ and $L \downarrow$ can be seen by regressing the hourly difference in the measure of $R_{n}$ against the sum of the hourly difference in $K \downarrow$ and $L \downarrow$ (Fig. 5). The slope of the best-fit line is very near unity while the $y$-intercept is $-7.5 \mathrm{~W} \mathrm{~m}^{-2}$.

The measurements of $R_{n}$ at Site 2 and the lysimeter in SEF (referred to as SL averaged $178 \mathrm{~W} \mathrm{~m}^{-2}$ and $187 \mathrm{~W} \mathrm{~m}^{-2}$, respectively, during the daytime period. Both the daytime MD of $9 \mathrm{~W} \mathrm{~m}^{-2}$ between these two measurements of $R_{n}$ and daytime MAD $\left(13 \mathrm{~W} \mathrm{~m}^{-2}\right)$ are less than the uncertainty estimates of the net radiometers and, thus, are not statistically significant.

The daytime mean $G$ for the NEF was $50 \mathrm{~W} \mathrm{~m}^{-2}$ and $37 \mathrm{~W} \mathrm{~m}^{-2}$, respectively, at Site 1 and NEL. For comparison, the daytime mean $G$ averaged over all 10 measurements collected at the intensive study site in NEF was $62 \mathrm{~W} \mathrm{~m}^{-2}$. The mean difference in $G$ measured at Site 1 and NEL was $13 \mathrm{~W} \mathrm{~m}^{-2}$. In contrast, the daytime MAD between the measurements of $G$ from Site 1 and NEL was nearly $40 \mathrm{~W} \mathrm{~m}^{-2}$; this suggests that there are compensating differences in the measurement of $G$ in NEF during the daytime and overnight periods. As can be seen in Fig. 6, which shows MD in the measurements on both daily and hourly timescales, these compensating errors are linked to the diurnal cycle. On the daily timescale, the daytime mean difference varied around $13 \mathrm{~W} \mathrm{~m}^{-2}$ with no evident temporal trend. On the hourly time scale, however, a clear temporal pattern emerges. From 0900 to noon, the measured $G$ at Site 1 is consistently greater than at NEL, typically by $47 \mathrm{~W} \mathrm{~m}^{-2}$; the period from noon to 1600 represents a transitional period; and, during the period from 1600 to 1900 , the measured $G$ at NEL was consistently greater than at Site 1 , typically by about $20 \mathrm{~W} \mathrm{~m}^{-2}$.

The hourly variations in the measurements of $G$ are similar in magnitude to the variability in the 10 measurements of $G$ at the intensive study locations. During the period from 0900 to noon, the mean of the variance in the measurements of $G$ calculated for each hourly period was $2682 \mathrm{~W}^{2} \mathrm{~m}^{-4}$; this corresponds to a mean standard deviation of $52 \mathrm{~W} \mathrm{~m}^{-2}$. For the study period as a whole, the daytime mean standard deviation was $51 \mathrm{~W} \mathrm{~m}^{-2}$ for NEF and $35 \mathrm{~W} \mathrm{~m}^{-2}$ when using the 10 measurements of $G$ collected at the

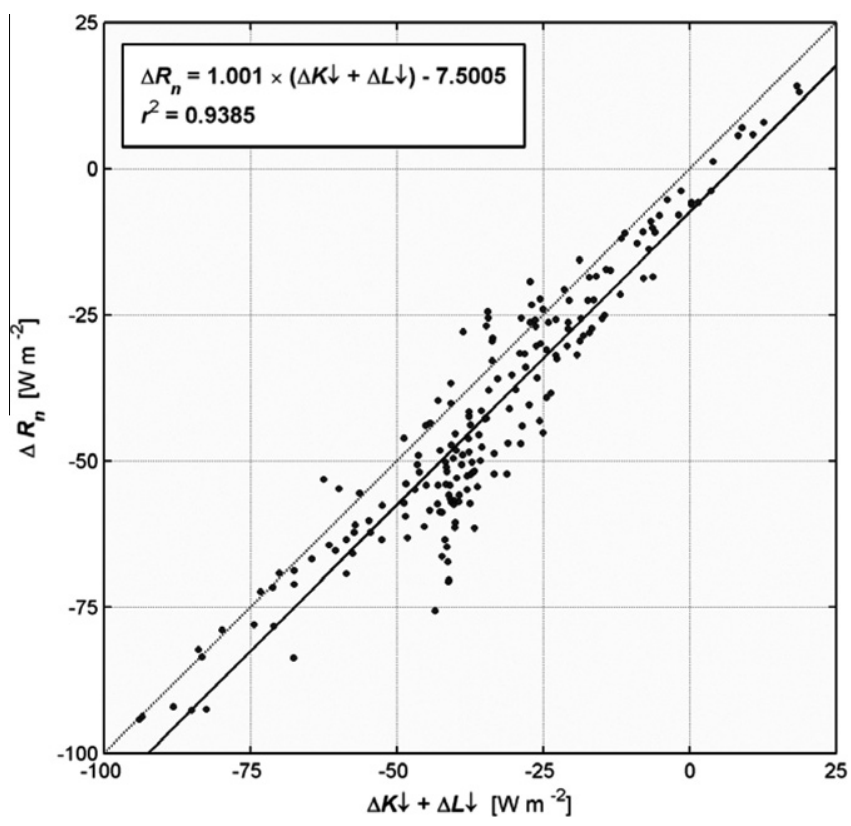

Fig. 5. The best-fit linear relationship between the hourly differences in net radiation and the sum of the differences in the incident components of the radiation budget is shown. 

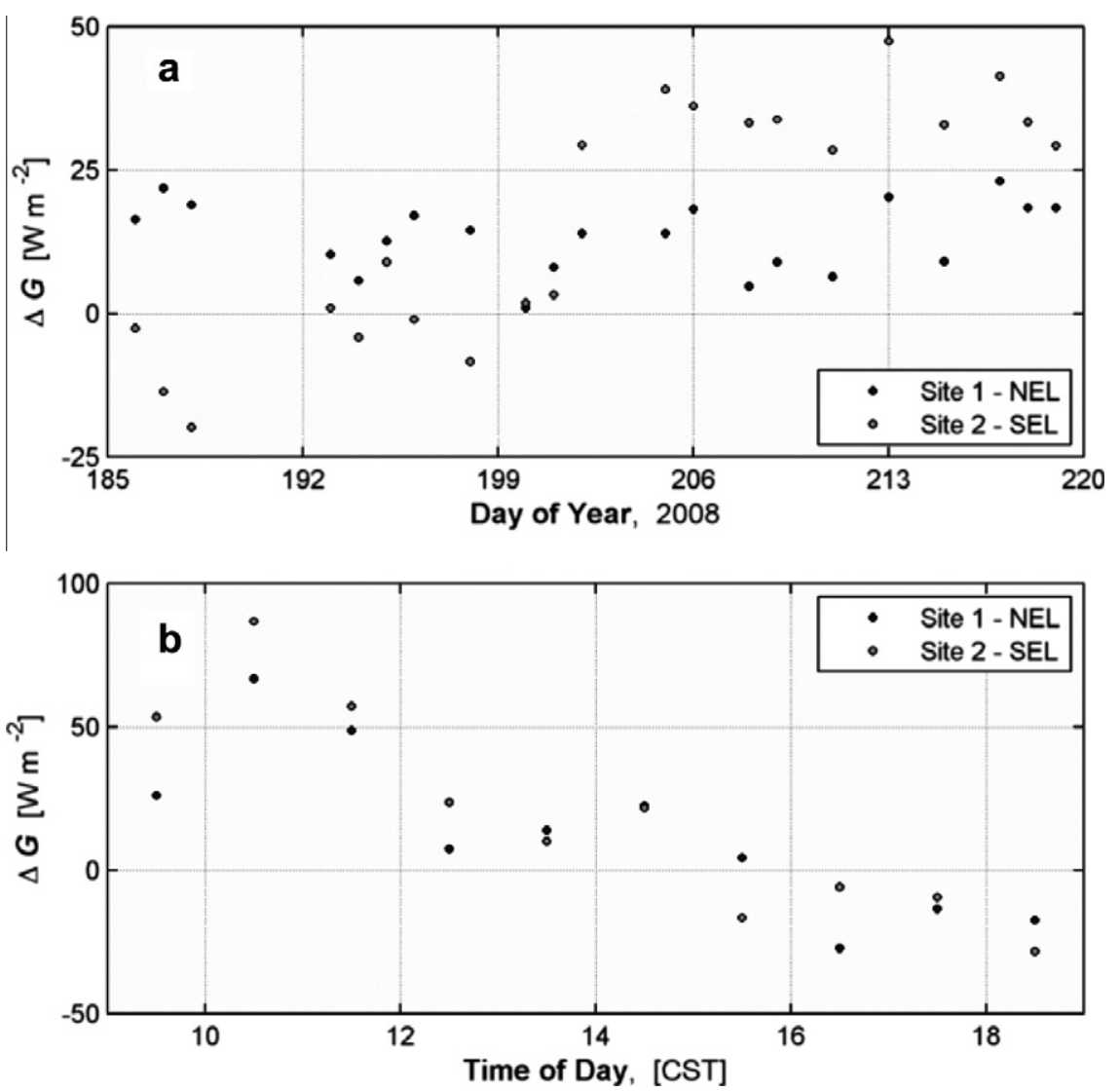

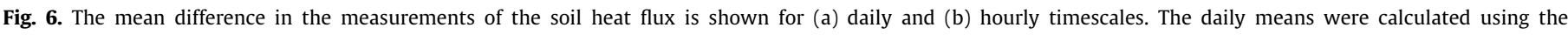
measurements collected during the daytime period only.

intensive study location in SF. Similarly, for the periods from noon to 1400 and 1400 to 1900 , the mean standard deviations were $65 \mathrm{~W} \mathrm{~m}^{-2}$ and $20 \mathrm{~W} \mathrm{~m}^{-2}$, respectively. This variability is similar to the spatial variability in $G$ found in other recent studies $[72,73]$ and suggests that the difference in $G$ observed in the NEF may be due to a shadowing effect which, in turn, is tied to variations in surface conditions, such as the amount of vegetation cover (see also ref. [86]). Additional analyses of the variability in LAI are presented below.

The analysis of the difference in $G$ as measured in SEF yielded similar results. For the whole of the study period, the daytime mean difference was $17 \mathrm{~W} \mathrm{~m}^{-2}$ with the measurements at Site 2 exceeding those at SEL. In this case, however, in addition to the hourly pattern in the mean difference, a long term trend in the daytime mean difference was evident (Fig. 6). More specifically, the daytime mean difference between the measurements at Site 2 and SEL increased linearly from approximately $-15 \mathrm{~W} \mathrm{~m}^{-2}$ on 4 July (DOY 186) to approximately $50 \mathrm{~W} \mathrm{~m}^{-2}$ on 8 August (DOY 220).

\subsection{Differences in the latent heat fluxes}

When the full 24-h was considered, the mean $\lambda E$ was $156 \mathrm{~W} \mathrm{~m}^{-2}, 176 \mathrm{~W} \mathrm{~m}^{-2}$, and $225 \mathrm{~W} \mathrm{~m}^{-2}$, respectively, for Site 1 , Site 8 , and NEL. The daily mean flux at NEL exceeded that measured at Site 1 by an average of $68 \mathrm{~W} \mathrm{~m}^{-2}$ with a maximum difference of $131 \mathrm{~W} \mathrm{~m}^{-2}$. Similarly, the flux at NEL consistently exceeded that measured at Site 8 (Fig. 7a). On average, the daily mean $\lambda E$ measured at NEL was $52 \mathrm{~W} \mathrm{~m}^{-2}$, greater than the daily mean $\lambda E$ measured at Site 8; the maximum difference between the two sites was $107 \mathrm{~W} \mathrm{~m}^{-2}$. In $\mathrm{SEF}$, the mean $\lambda E$ was $128 \mathrm{~W} \mathrm{~m}^{-2}, 149 \mathrm{~W} \mathrm{~m}^{-2}$, and $204 \mathrm{~W} \mathrm{~m}^{-2}$, respectively, for Site 2 , Site 9, and SEL with the measurements at SEL again consistently exceeded those of the two EC systems (Fig. 7b). On average $\lambda E$ measured at SEL was $76 \mathrm{~W} \mathrm{~m}^{-2}$ greater than that measured at Site 2 and $55 \mathrm{~W} \mathrm{~m}^{-2}$ greater than that measured at Site 9 .

The mean daytime $\lambda E$ at Site 1 , Site 8 , and NEL were $317 \mathrm{~W} \mathrm{~m}^{-2}$, $348 \mathrm{~W} \mathrm{~m}^{-2}$, and $473 \mathrm{~W} \mathrm{~m}^{-2}$, respectively. During the day, $\lambda E$ measured at NEL exceeded the measurements at Site 1 by $157 \mathrm{~W} \mathrm{~m}^{-2}$ and the measurements at Site 8 by $126 \mathrm{~W} \mathrm{~m}^{-2}$, on average. It is well known that EC method often fails to close the energy budget [74-76]; and, incomplete closure is likely a partial cause of this discrepancy. To account for the effects of partial closure, closure was forced while maintaining a constant Bowen ratio $(\beta)$ following the method described by Blanken et al. [77] and Twine et al. [78] and others.

However, in light of the results of the comparative analysis discussed previously, the available energy $(A)$ was not calculated exclusively from site-specific measurements. The net radiation was calculated using the site-specific measurements of the upwelling shortwave $(K \uparrow)$ and longwave radiation $(L \uparrow)$ and the means of $K \downarrow$ and $L \downarrow$ from the six net radiometers in NEF, SEF, and the adjacent fields, all of which were located within $320 \mathrm{~m}$ of one another, and thus, would be expected to agree closely. The soil heat flux estimates for the EC sites were calculated as the mean of the site-specific measurements and the ten measurements of $G$ from the intensive study site in the field. After this adjustment, the estimates of $A$ for NEF agreed to within $15 \mathrm{~W} \mathrm{~m}^{-2}$ during the day; for $\mathrm{SEF}$, they agreed to within $3 \mathrm{~W} \mathrm{~m}^{-2}$. Using these calculations of $A$, the percent closure for each of the EC sites ranged from a low of $74 \%$ at Site 2 to a maximum of $87 \%$ at Site 8 . The percent closure for Site 1 and Site 9 were $84 \%$ and $85 \%$, respectively.

After adjusting the turbulent fluxes to force closure, the daytime moisture flux measured at Site 1 was, on average, $26 \mathrm{~W} \mathrm{~m}^{-2}$ [standard deviation $(\sigma)=19 \mathrm{~W} \mathrm{~m}^{-2}$ ] less than the flux measured 

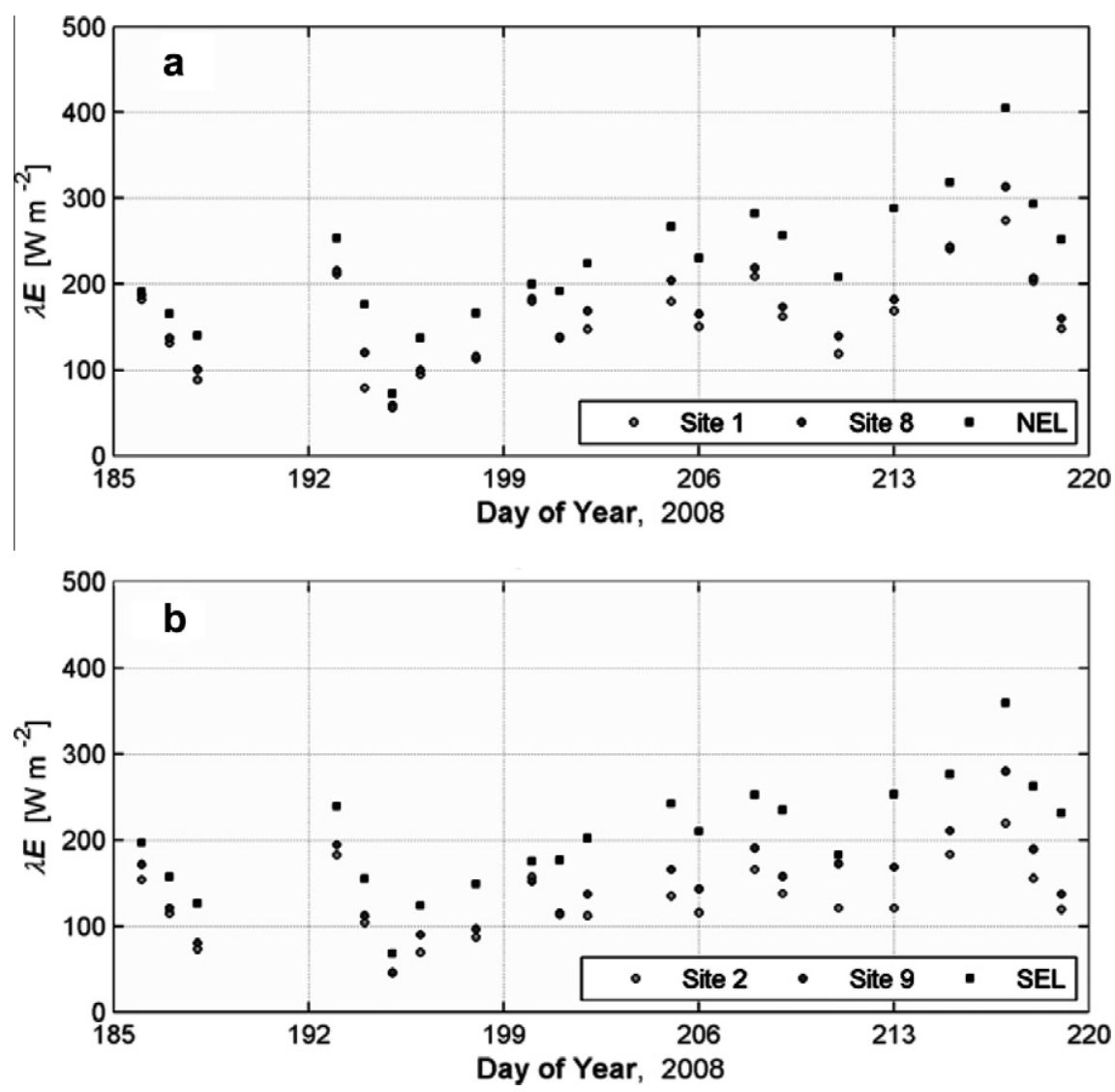

Fig. 7. The daily mean latent heat fluxes measured in (a) the Northeast Field and (b) the Southeast Field are shown.
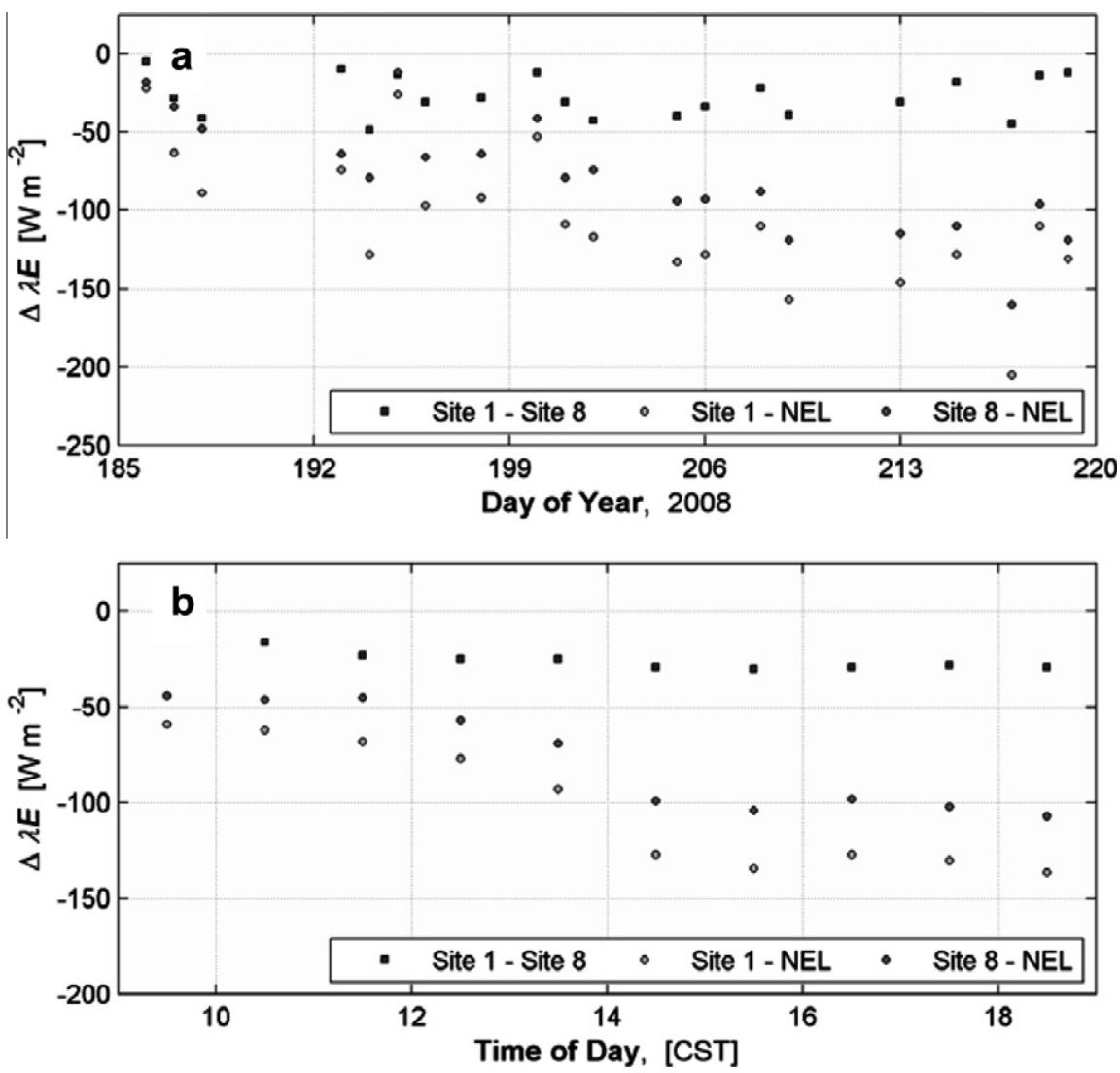

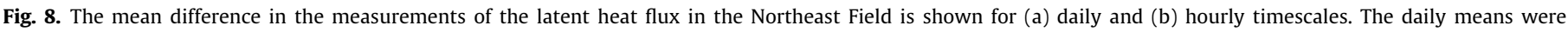
calculated using the measurements collected during the daytime period only. 
at Site 8 . At the same time, the measurements at Site 1 were, on average, $102 \mathrm{~W} \mathrm{~m}^{-2}\left(\sigma=73 \mathrm{~W} \mathrm{~m}^{-2}\right)$ less than at NEL and the measurements at Site 8 were, on average, $76 \mathrm{~W} \mathrm{~m}^{-2}\left(\sigma=64 \mathrm{~W} \mathrm{~m}^{-2}\right)$ less than at NEL. On a day-to-day basis, however, there was significant variability in the discrepancy between EC and LY-based measurements of $\lambda E$ in NEF; moreover, there was a tendency for the magnitude of the difference between the EC stations and NEL to be larger later in the study period (Fig. 8a). For example, the daytime $\mathrm{MD}_{1, \mathrm{~N}}$ decreased from $-5 \mathrm{~W} \mathrm{~m}^{-2}\left(\sigma=73 \mathrm{~W} \mathrm{~m}^{-2}\right)$ on 4 July
(DOY 186 ) to $-128 \mathrm{~W} \mathrm{~m}^{-2}$ ( $\sigma=27 \mathrm{~W} \mathrm{~m}^{-2}$ ) on 26 July (DOY 208); $\mathrm{MD}_{1, \mathrm{~N}}$ remained consistently near $130 \mathrm{~W} \mathrm{~m}^{-2}$ for the remainder of the study period. The daytime $\mathrm{MD}_{8, \mathrm{~N}}$ showed the same curvilinear pattern decreasing from $-20 \mathrm{~W} \mathrm{~m}^{-2}\left(\sigma=69 \mathrm{~W} \mathrm{~m}^{-2}\right)$ to $-93 \mathrm{~W} \mathrm{~m}^{-2}\left(\sigma=65 \mathrm{~W} \mathrm{~m}^{-2}\right)$.

On an hourly basis, the mean difference between the measurements in NEF showed a clear temporal pattern with MD related to time of day by a quadratic relationship (Fig. 8b; Table 1). Smaller differences occurred earlier in the day and the maximum

Table 1


of determination.

\begin{tabular}{|c|c|c|c|c|}
\hline \multirow[t]{2}{*}{ Mean difference } & \multicolumn{3}{|c|}{ Fitting coefficients } & \multirow[t]{2}{*}{ Coefficient of determination } \\
\hline & $a$ & $B$ & $C$ & \\
\hline \multicolumn{5}{|l|}{ Latent heat flux } \\
\hline $\mathrm{MD}_{1,8}$ & 0.308 & -10.293 & 56.368 & 0.961 \\
\hline $\mathrm{MD}_{1, \mathrm{~N}}$ & 1.969 & -69.251 & 473.722 & 0.927 \\
\hline $\mathrm{MD}_{8, \mathrm{~N}}$ & 1.756 & -61.651 & 435.275 & 0.932 \\
\hline $\mathrm{MD}_{2,9}$ & 0.826 & -21.209 & 123.309 & 0.932 \\
\hline $\mathrm{MD}_{2, \mathrm{~S}}$ & 0.269 & -15.147 & 104.015 & 0.831 \\
\hline $\mathrm{MD}_{9, \mathrm{~S}}$ & 0.095 & -13.141 & 96.977 & 0.885 \\
\hline \multicolumn{5}{|l|}{ Sensible heat flux } \\
\hline $\mathrm{MD}_{1,8}$ & -0.584 & 17.769 & -113.350 & 0.921 \\
\hline $\mathrm{MD}_{1, \mathrm{~N}}$ & -1.664 & 67.085 & -521.833 & 0.993 \\
\hline $\mathrm{MD}_{8, \mathrm{~N}}$ & -1.061 & 48.862 & -406.416 & 0.988 \\
\hline $\mathrm{MD}_{2,9}$ & -0.348 & 12.584 & -96.367 & 0.205 \\
\hline $\mathrm{MD}_{2, \mathrm{~S}}$ & -2.497 & 91.132 & -672.897 & 0.866 \\
\hline $\mathrm{MD}_{9, \mathrm{~S}}$ & -2.176 & 79.261 & -580.685 & 0.884 \\
\hline
\end{tabular}
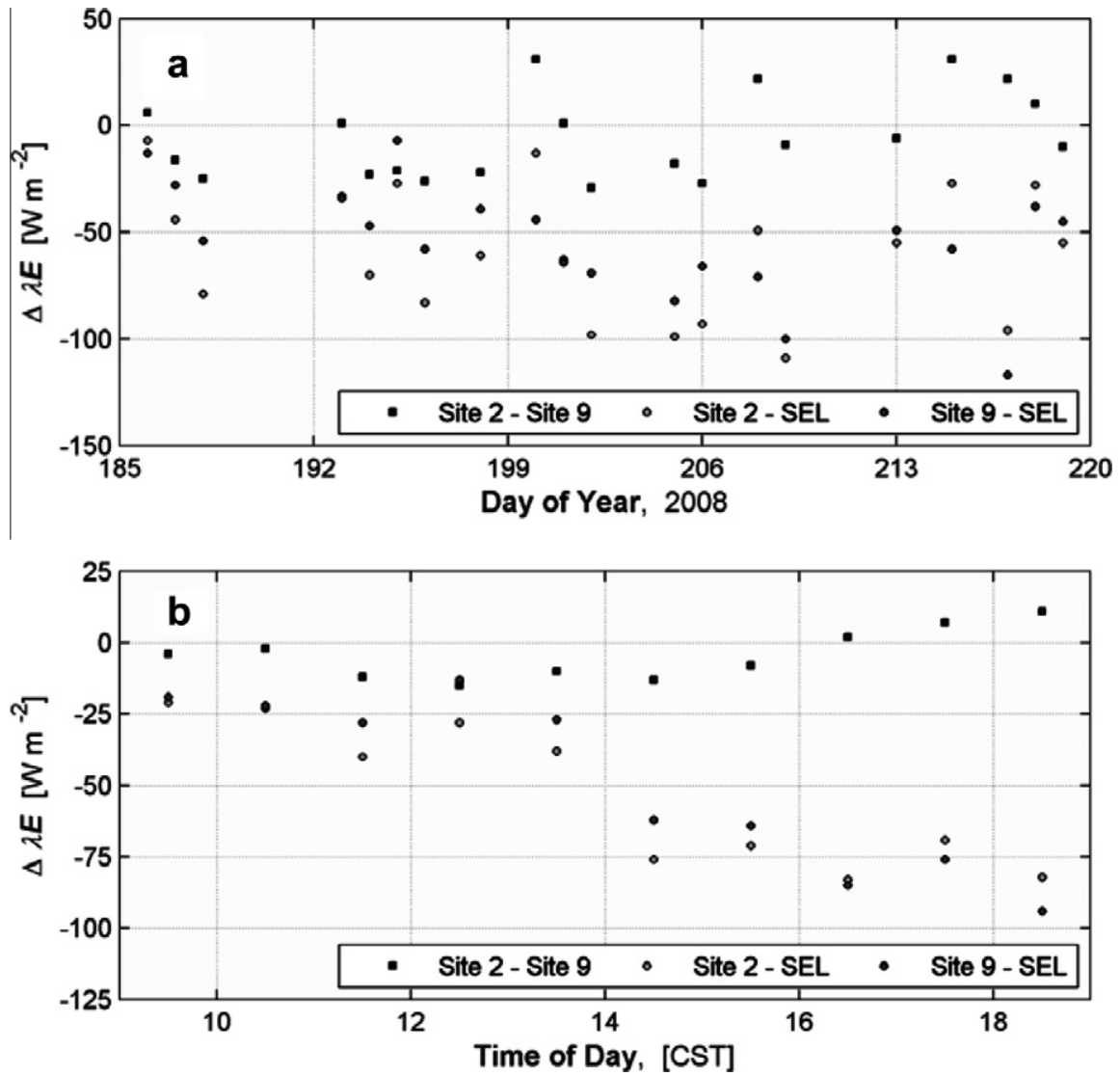

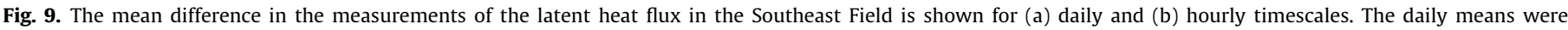
calculated using the measurements collected during the daytime period only. 
difference occurred near 1700 . For example, the hourly $\mathrm{MD}_{1,8}$ decreased from $14 \mathrm{~W} \mathrm{~m}^{-2}\left(\sigma=29 \mathrm{~W} \mathrm{~m}^{-2}\right)$ at 0930 to $-29 \mathrm{~W} \mathrm{~m}^{-2}$ $\left(\sigma=14 \mathrm{~W} \mathrm{~m}^{-2}\right)$ at 1730 .

After forcing closure the mean daytime $\lambda E$ in SEF was 377 $\mathrm{W} \mathrm{m} \mathrm{m}^{-2}, 381 \mathrm{~W} \mathrm{~m}^{-2}$, and $433 \mathrm{~W} \mathrm{~m}^{-2}$, respectively, for Site 2 , Site 9, and SEL. The daytime $\mathrm{MD}_{2,9}$ was $-4 \mathrm{~W} \mathrm{~m}^{-2}$ while $\mathrm{MD}_{2, \mathrm{~S}}$ was $-56 \mathrm{~W} \mathrm{~m}^{-2}$ and $\mathrm{MD}_{9, \mathrm{~s}}$ was $-52 \mathrm{~W} \mathrm{~m}^{-2}$. In contrast to the measurements collected in NEF, there were no clear trends in the dayto-day variability in SEF (Fig. 9). The hourly MD, however, showed a similar quadratic relationship with time of day as seen with the difference measurements in the NEF (Table 1).

Although other studies, such as Prueger et al. [79], have suggested assigning the full residual to $\lambda E$ under advective conditions, forcing closure by this method did not substantially alter the results. For the EC systems in both NEF and SEF, assigning the fully residual to $\lambda E$ in lieu of partitioning the residual in proportion to $\beta$ typically resulted in less than $10 \mathrm{~W} \mathrm{~m}^{-2}$ increase in the flux. For NEF, $\mathrm{MD}_{1,8}$ was reduced by approximately $6 \mathrm{~W} \mathrm{~m}^{-2}$ to 20 $\mathrm{W} \mathrm{m}{ }^{-2}$. Similarly, $\mathrm{MD}_{1, \mathrm{~N}}$ and $\mathrm{MD}_{8, \mathrm{~N}}$ were $-91 \mathrm{~W} \mathrm{~m}^{-2}$ and $71 \mathrm{~W}$ $\mathrm{m}^{-2}$. For $\mathrm{SEF}, \mathrm{MD}_{2,9}, \mathrm{MD}_{2, \mathrm{~s}}$, and $\mathrm{MS}_{9, \mathrm{~S}}$ were $-1 \mathrm{~W} \mathrm{~m}^{-2},-52 \mathrm{~W}$ $\mathrm{m}^{-2},-51 \mathrm{~W} \mathrm{~m}^{-2}$, respectively. This result is not altogether unexpected given the low values of $\beta$; the daytime mean ranged only from 0.15 at Site 8 to 0.23 at Site 2 .

\subsection{Differences in the sensible heat fluxes}

Not unexpectedly, $H$ in both the NEF and SEF mirrored $\lambda E$. For the whole of the field campaign, the daytime mean $H$ at Site 1, Site 8 , and NEL was $51 \mathrm{~W} \mathrm{~m}^{-2}, 34 \mathrm{~W} \mathrm{~m}^{-2}$, and $-34 \mathrm{~W} \mathrm{~m}^{-2}$, respectively, after forcing closure of the surface energy budget. Note that closure is always forced for the lysimetric measurements because
$H$ is not measured independently of the other components of the surface energy budget; rather, it is calculated as the residual of the surface energy budget. Similarly, the daytime mean $H$ at Site 2 , Site 9 , and SEL was $49 \mathrm{~W} \mathrm{~m}^{-2}, 39 \mathrm{~W} \mathrm{~m}^{-2}$, and $-58 \mathrm{~W} \mathrm{~m}^{-2}$, respectively. On a daily basis, the magnitude of the daytime mean $H$ tended to decrease for both fields. For example, $H$ at Site 1 decreasing from approximately $150 \mathrm{~W} \mathrm{~m}^{-2}$ at the beginning of the study period to near $-100 \mathrm{~W} \mathrm{~m}^{-2}$ at the end of the study period. The daytime $\mathrm{MD}_{1,8}$ was $17 \mathrm{~W} \mathrm{~m}{ }^{-2}\left(\sigma=10 \mathrm{~W} \mathrm{~m}^{-2}\right)$ while $\mathrm{MD}_{1, \mathrm{~N}}$ was $85 \mathrm{~W} \mathrm{~m}^{-2}\left(\sigma=65 \mathrm{~W} \mathrm{~m}^{-2}\right)$ and $\mathrm{MD}_{8, \mathrm{~N}}$ was $68 \mathrm{~W} \mathrm{~m}^{-2}(\sigma=64$ $\left.\mathrm{W} \mathrm{m}^{-2}\right)$. The daytime $\mathrm{MD}_{2,9}$ was $10 \mathrm{~W} \mathrm{~m}^{-2}\left(\sigma=31 \mathrm{~W} \mathrm{~m}^{-2}\right)$ while $\mathrm{MD}_{2, \mathrm{~S}}$ was $107 \mathrm{~W} \mathrm{~m}^{-2}\left(\sigma=73 \mathrm{~W} \mathrm{~m}^{-2}\right)$ and $\mathrm{MD}_{9, \mathrm{~S}}$ was $97 \mathrm{~W} \mathrm{~m}^{-2}$ $\left(\sigma=60 \mathrm{~W} \mathrm{~m}^{-2}\right)$. The magnitude of difference between the EC systems and LY-based measurements of $H$ tended to increase over time on both daily and hourly time scales (Figs. 10 and 11; Table 1).

\subsection{Spatial variations in leaf area index and soil moisture}

Although the observed discrepancies in the turbulent fluxes between the paired EC systems in each of the fields were due, at least in part, to measurement uncertainty, after forcing closure of the surface energy budget, these differences were relatively minor compared to the differences still remaining between EC and LYbased measurements in each field. One potential reason for the discrepancy is spatial heterogeneity in surface conditions within the field. In order to explore this, the LAI maps for each field were analyzed in order to ascertain the degree of spatial variability in the fields and the differences in the vegetation density within the source areas of the EC systems and lysimeters.

An analysis of LAI in both NEF and SEF showed that the fields transitioned from essentially bare soil to fully vegetated
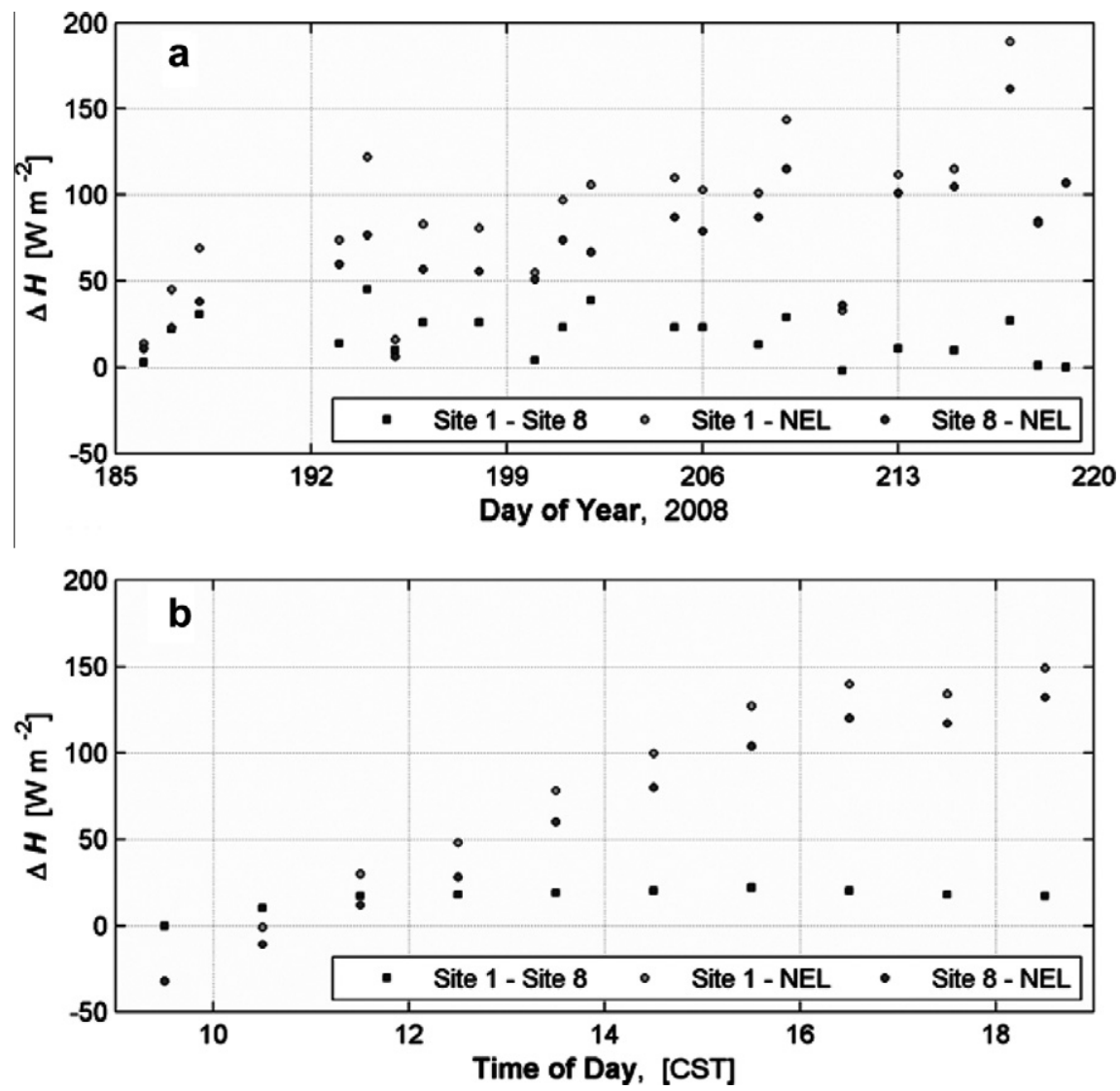

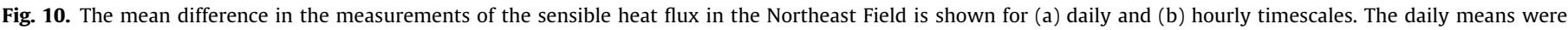
calculated using the measurements collected during the daytime period only. 

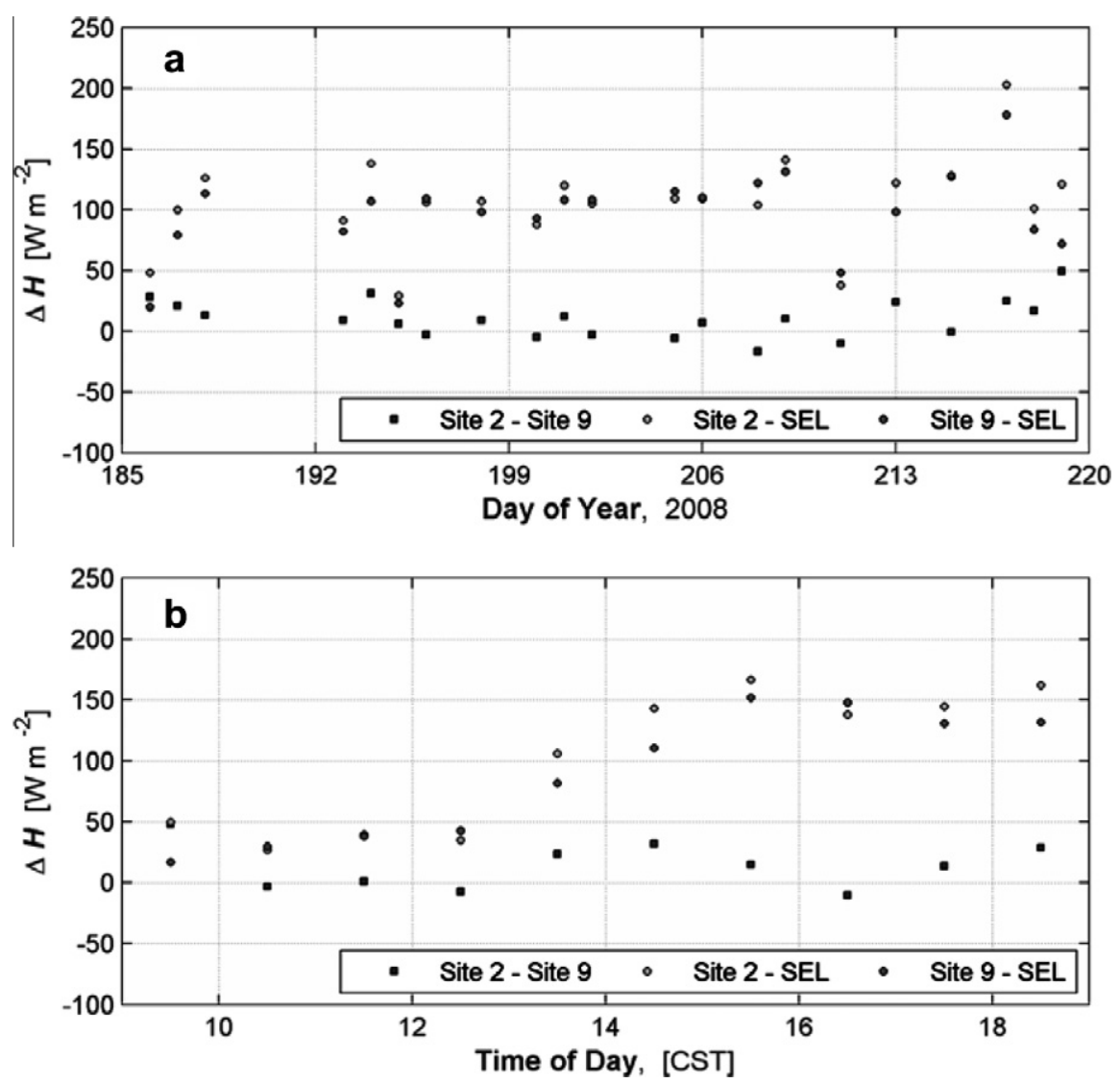

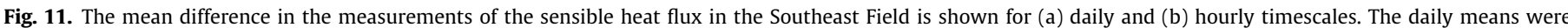
calculated using the measurements collected during the daytime period only.

Table 2

Summary statistics describing the variability of the leaf area index in the Northeast and Southeast fields as determined from aerial imagery collected on the dates show

\begin{tabular}{|c|c|c|c|c|c|c|}
\hline Calendar Date & 26 June & 12 July & 20 July & 28 July & 5 August & 13 August \\
\hline Day of Year & 178 & 194 & 202 & 210 & 218 & 226 \\
\hline \multicolumn{7}{|l|}{ Northeast field } \\
\hline Mean & 0.023 & 0.478 & 1.597 & 2.563 & 3.132 & 3.444 \\
\hline Standard deviation & 0.005 & 0.196 & 0.563 & 0.494 & 0.232 & 0.058 \\
\hline Coefficient of variation & 0.217 & 0.410 & 0.352 & 0.193 & 0.074 & 0.017 \\
\hline Variance & $2.02 \times 10^{-5}$ & 0.039 & 0.317 & 0.244 & 0.054 & 0.003 \\
\hline Spatial variance & $2.15 \times 10^{-5}$ & 0.029 & 0.318 & 0.172 & 0.044 & 0.002 \\
\hline Non-spatial variance & $2.69 \times 10^{-6}$ & 0.001 & $1.01 \times 10-7$ & 0.074 & 0.008 & 0.001 \\
\hline Total variance & $2.42 \times 10^{-5}$ & 0.030 & 0.318 & 0.246 & 0.052 & 0.003 \\
\hline Percent contribution & 89 & 97 & 100 & 70 & 85 & 72 \\
\hline Percent contribution of non-spatial variability & 11 & 3 & 0 & 30 & 15 & 28 \\
\hline \multicolumn{7}{|l|}{ Southeast field } \\
\hline Mean & 0.019 & 0.512 & 1.52 & 2.53 & 3.39 & 3.48 \\
\hline Standard deviation & 0.004 & 0.220 & 0.592 & 0.601 & 0.157 & 0.086 \\
\hline Coefficient of variation & 0.211 & 0.429 & 0.389 & 0.238 & 0.046 & 0.0245 \\
\hline Variance & $1.44 \times 10^{-5}$ & 0.048 & 0.351 & 0.361 & 0.025 & 0.007 \\
\hline Spatial variance & $1.29 \times 10^{-5}$ & 0.032 & 0.224 & 0.109 & 0.001 & $6.26 \times 10^{-5}$ \\
\hline Non-spatial variance & $1.31 \times 10^{-6}$ & 0.014 & 0.168 & 0.213 & 0.028 & 0.006 \\
\hline Total variance & $1.42 \times 10^{-5}$ & 0.046 & 0.393 & 0.324 & 0.029 & 0.006 \\
\hline Percent contribution of spatial variability & 91 & 69 & 57 & 34 & 4 & 1 \\
\hline Percent contribution of non-spatial variability & 9 & 31 & 43 & 66 & 96 & 99 \\
\hline
\end{tabular}

over the course of the study period (Table 2). It also showed that the greatest variability in the vegetation density occurred during the intermediate weeks of the field campaign, more specifically, during the period from 20 July (DOY 202) and 28 July (DOY 210). In NEF, the spatial component of the variability contributed between $60 \%$ and $100 \%$ of the total variance. This suggests that the patchy character of NEF remained throughout the field campaign. In contrast, the spatial component of the variability was initially quite significant, accounting for $91 \%$ of the total variance on June 26 (DOY 178), but decreased in a linear manner over time to account for only $10 \%$ of the total variance on 13 August (DOY 226). This suggests that there was substantial spatial variability in LAI at the outset of the field campaign, but once the cotton crop was fully developed with nearly $100 \%$ cover, the variability was largely due to measurement uncertainty. 
By overlaying the flux footprint atop the maps of LAI (Fig. 12), it was possible to extract and compare LAI measurements within the source area of the EC stations and lysimeters.

In NEF, the comparison revealed significant differences in the vegetation density not only among the source areas of the various sensor systems, but also for NEF as a whole. As can be seen in Fig. 13, LAI within the footprint of Site 1 was consistently lower than in the footprint of Site 8 or NEL. It was typically also lower than the average for NEF as a whole. The difference in LAI between Site 1 and NEL was as great as $1.5 \mathrm{~m}^{2} \mathrm{~m}^{-2}$; this occurred on 20 July (DOY 202). Similarly, the maximum difference between LAI within the footprint of Site 8 and NEL was $0.9 \mathrm{~m}^{2} \mathrm{~m}^{-2}$ and also occurred on 20 July (DOY 202). This suggests that the surface contributing to the fluxes measured by the EC stations and NEL were quite different and, as a result the measurements were not necessarily representative of either the portion of the field outside of the measurement source area or NEF as a whole. This is especially true for NEL where LAI was as much as $1.4 \mathrm{~m}^{2} \mathrm{~m}^{-2}$ greater than the field average. For the six days when LAI maps were available, LAI at NEL averaged more than $0.5 \mathrm{~m}^{2} \mathrm{~m}^{-2}$ greater than the mean LAI of the entire NEF.

The differences in rate of growth and amount of vegetation cover in NEF can also be seen in the differences in the best-fit relationship between LAI and day of year (Table 3 ). The best-fit relationship is sigmoidal and has the form:

$\widehat{L}=\frac{a}{1+\exp \left[\frac{-\left(J-J_{0}\right)}{b}\right]}$ where $\widehat{L}$ is the predicted LAI, $J$ is the day of year, $a$ is the scaling coefficient, $b$ is the shape coefficient, and $J_{0}$ is the offset coefficient indicating the date when inflection of the best-fit curve occurs. For $\mathrm{NEF}, a$ had a constant value of $3.5 \mathrm{~m}^{2} \mathrm{~m}^{-2}$. A comparison of the $b$ coefficient, however, showed that while the shape coefficients for Site 1 and Site 8 were similar to one another and to the value for the field as a whole, the coefficient associated with NEL was substantially smaller. As a result, the slope of the straight-line portion of best-fit curve for NEL was nearly twice that of the slope for the other locations in the field. For example, the slope of the straightline portion of best-fit curve for Site 1 was 0.13 while the slope of the straight-line portion of best-fit curve for NEL was 0.24 . This indicates that the vegetation was growing much more rapidly within the lysimeter than in other parts of NEF. This is confirmed by the crop height and width measurements collected in the field and in the lysimeter indicating more developed cotton growing in the lysimeter (see ref. [85]). A comparison of $J_{0}$ reaffirms this by indicating that the LAI of the cotton in NEL was between five and nine days ahead of the LAI in other parts of the field.

The leaf area index in SEF also exhibited variations within the source areas of the EC systems and lysimeter in that field. The difference, however, was not as pronounced (Fig. 14). For example, for the six maps evaluated as a part of this study, the mean difference between the LAI at Site 2 and Site 9 was $0.02 \mathrm{~m}^{2} \mathrm{~m}^{-2}$ with a maximum difference of $0.2 \mathrm{~m}^{2} \mathrm{~m}^{-2}$. Comparisons of LAI within the source area of the various measurement systems in SEF showed that LAI within the source area of all three systems tended to be somewhat greater than the mean for the field as a whole. In the case of both Site 2 and Site 9, this difference was less than

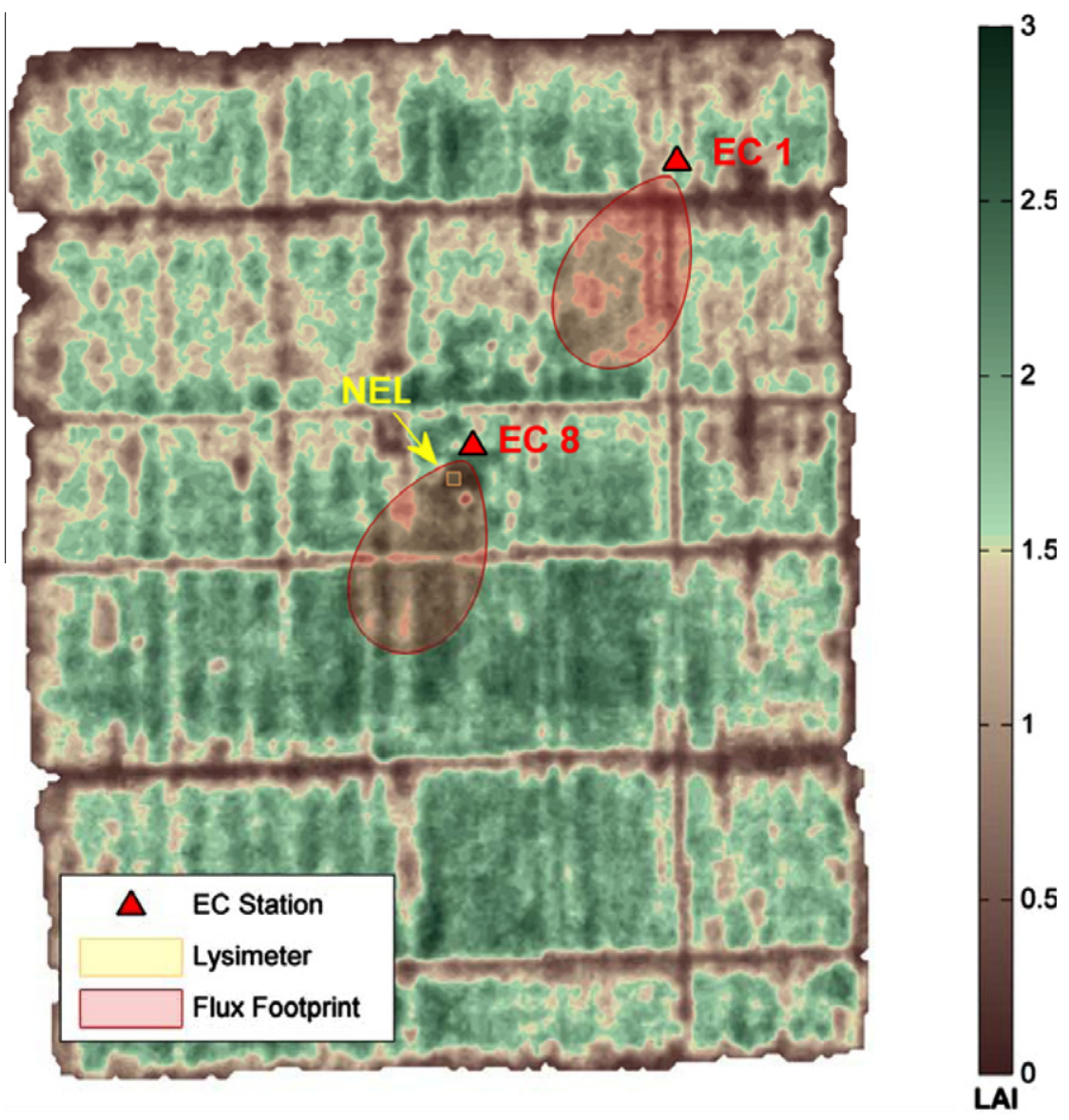

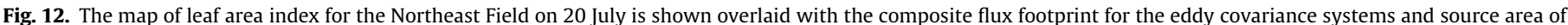
the lysimeter. 

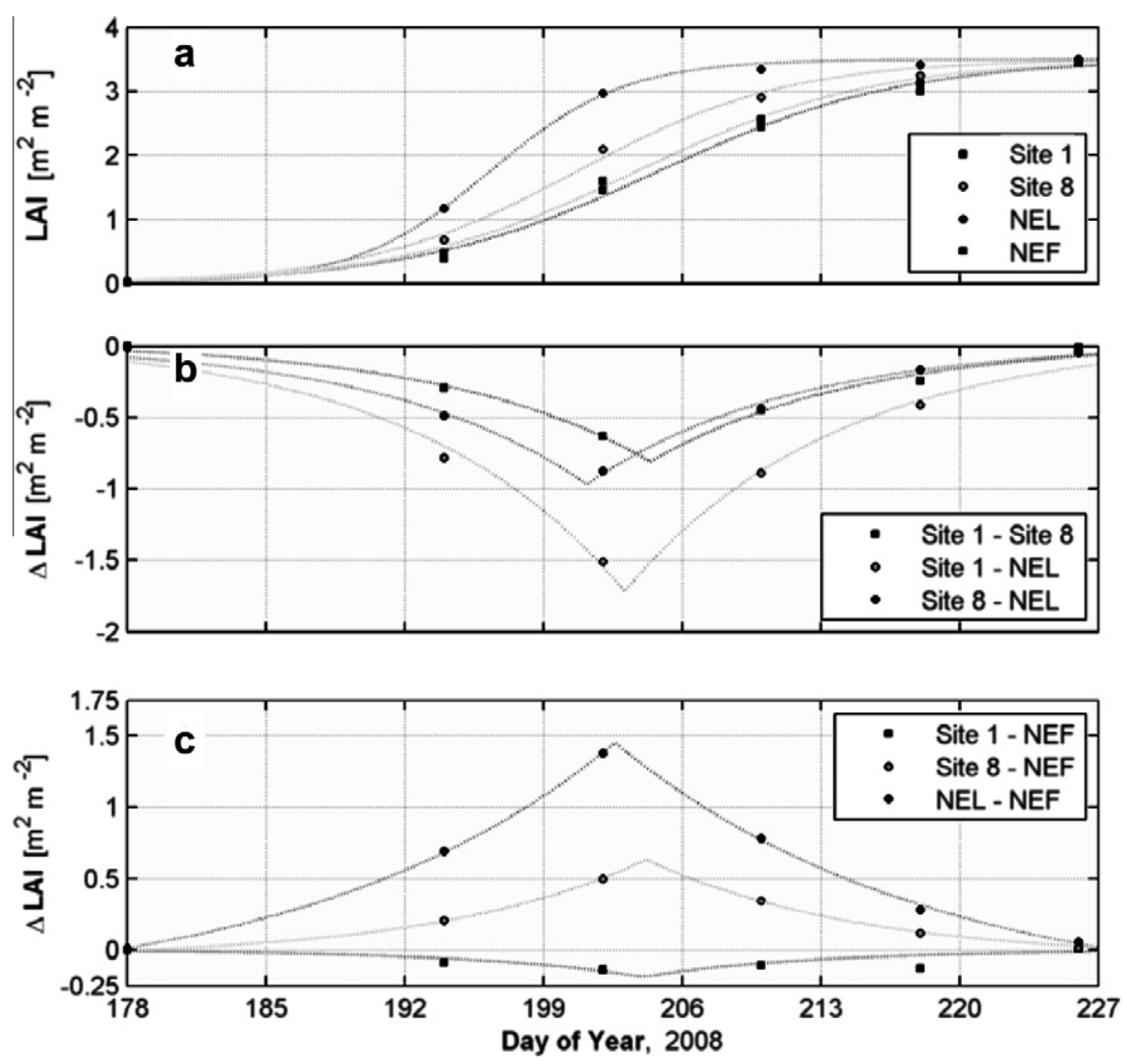

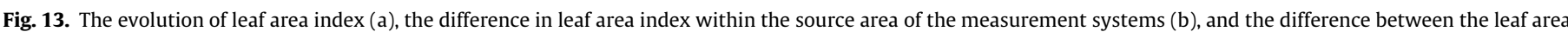
index of the Northeast Field as a whole and the source area of the measurement systems (c) are shown. The dash lines indicate the best-fit relationships.

Table 3

Coefficients for the sigmoidal best-fit relationship describing the change in leaf area index over time.

\begin{tabular}{lllll}
\hline Site/location & \multicolumn{2}{l}{ Fitting coefficients } & \multirow{2}{l}{$\begin{array}{l}\text { Coefficient of } \\
\text { determination }\end{array}$} \\
\cline { 2 - 3 } & $a$ & $B$ & $J_{0}$ & \\
\hline Northeast field & & & & \\
Site 1 & 3.5 & 6.2 & 205 & 0.997 \\
Site 8 & 3.5 & 5.4 & 201 & 0.998 \\
NE lysimeter & 3.5 & 3.4 & 196 & 0.999 \\
Entire field & 3.5 & 6.0 & 204 & 0.998 \\
Southeast field & & & & \\
Site 2 & 3.5 & 4.5 & 203 & 1.000 \\
Site 9 & 3.5 & 5.3 & 203 & 0.999 \\
SE lysimeter & 3.5 & 4.3 & 201 & 1.000 \\
Entire field & 3.5 & 5.5 & 203 & 0.998 \\
\hline
\end{tabular}

$0.1 \mathrm{~m}^{2} \mathrm{~m}^{-2}$ while in the case of SEL, it was $0.2 \mathrm{~m}^{2} \mathrm{~m}^{-2}$. The maximum difference occurred on 28 July (DOY 210) and was 0.4 $\mathrm{m}^{2} \mathrm{~m}^{-2}, 0.2 \mathrm{~m}^{2} \mathrm{~m}^{-2}$, and $0.6 \mathrm{~m}^{2} \mathrm{~m}^{-2}$, respectively, for Site 2 , Site 9, and SEL.

Both the LAI maps (e.g. Fig. 15) and a comparison of the fitting coefficients for the measurement locations in SEF also indicate greater homogeneity in the vegetation density in SEF. The scaling coefficients ranged only from 4.3 at SEL to 5.5 for the whole of SEF; correspondingly, the slope of the straight-line portion of best-fit curves ranged only between 0.15 and 0.17 . Furthermore, $J_{0}$ was 203 for all of the curves except the best-fit curve for SL where it was 201. As was the case in NEF, the LAI within the lysimeter was most different from that of SEF as a whole; this suggests that the conditions within SEL were the least representative of the field as a whole.
Variographic analyses of the measurements collected by the soil moisture network were also conducted. More specifically, the separate analyses were conducted using the data collected in each field on days without rain or irrigation events. The analysis of $\theta$ using the five measurements collected by the soil moisture network in NEF indicated that there was no spatial correlation among the measurements; it also showed the average variance among the measurements was $1.66 \times 10^{-4} \mathrm{~m}^{6} \mathrm{~m}^{-6}$ (equivalently, a standard deviation of $0.0129 \mathrm{~m}^{3} \mathrm{~m}^{-3}$ ). A similar analysis of the data from SEF indicated there was no spatial correlation among the measurements from the five sensors there. The mean variance for the measurement in SEF was $1.22 \times 10^{-4} \mathrm{~m}^{6} \mathrm{~m}^{-6}$ (equivalently, a standard deviation of $0.0110 \mathrm{~m}^{3} \mathrm{~m}^{-3}$ ). The variability observed in the measurements from each field is less than the measurement uncertainty of the soil moisture sensors $\left(0.024 \mathrm{~m}^{3} \mathrm{~m}^{-3}\right)$ reported by Cosh et al. (2012). This result, which is consistent with not only two other studies using BEAREX08 data (see Cosh et al., 2012; Evett et al., [85]) but also a prior study at the same site by Evett et al. [46], suggests that $\theta$ can be considered uniform for both NEF and SEF.

It is well known that surface properties play a central role in regulating the exchange of heat and moisture between the land surface and the atmosphere. For example, vegetation can influence the magnitude and partition of the surface energy fluxes both directly through its effects on albedo, surface roughness, and surface temperature and indirectly through a number of biophysical mechanisms and feedbacks [80-82]. Moreover, these effects can differ over short distances due to fine-scale spatial variations in surface properties [83]. Although it is difficult, in this case, to quantify the effects of the variations in LAI on the moisture fluxes on short time scales, the recent analysis of the water budget in NEF 

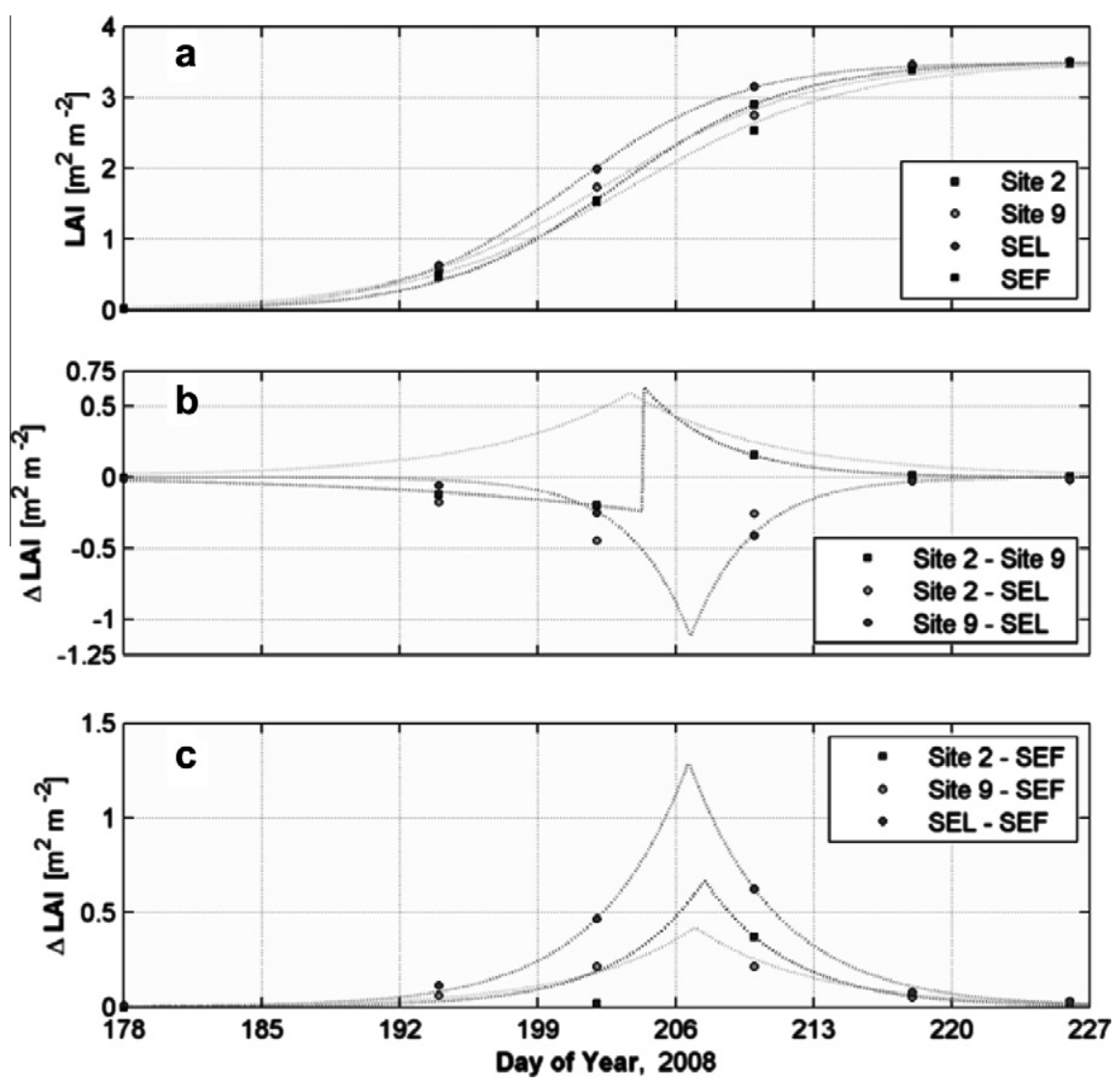

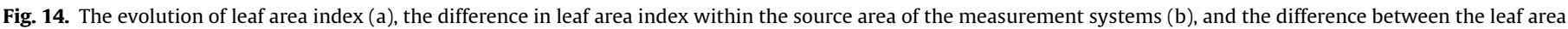
index of the Southeast Field as a whole and the source area of the measurement systems (c) are shown. The dash lines indicate the best-fit relationships.

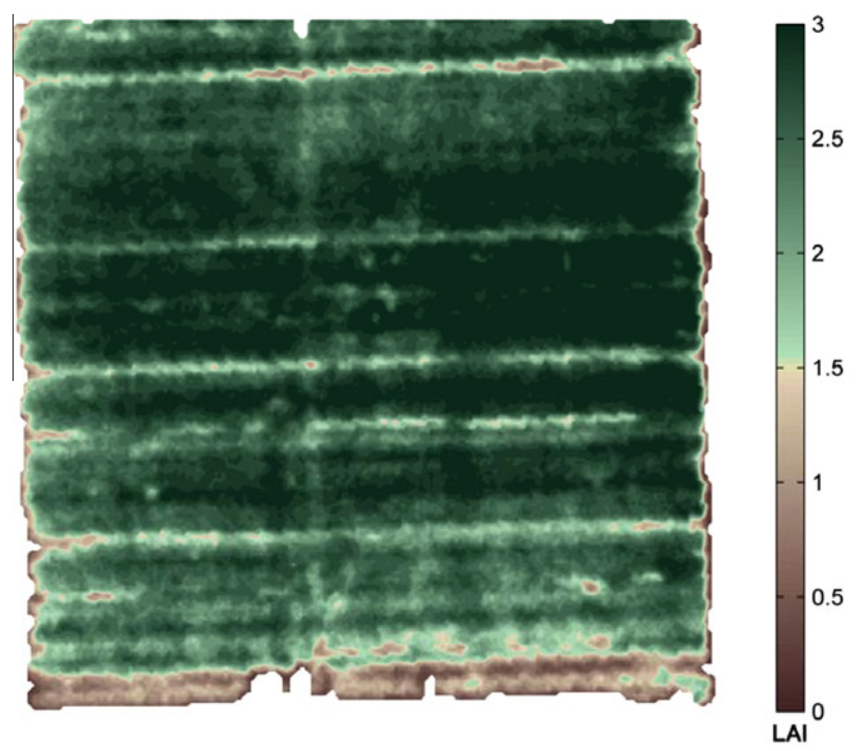

Fig. 15. A map of the leaf area index derived from aircraft imagery of the Southeast Field collected on 28 July.

and SEF by Evett et al. [85] suggests that the increased vegetation in NEL resulted in an increase in $\lambda E$ of approximately $15-20 \%$ during the study period. Using the $15 \%$ as the conservative estimate of the effects of the difference in LAI, the greater vegetation density in NEL as compared to the whole of NEF would result in an average difference of $60 \mathrm{~W} \mathrm{~m}^{-2}$ in the observed $\lambda E$ during the day as mea- sured by the EC stations and lysimeter. It is important to note that this is an average difference. In actuality, it is quite likely that the differences in vegetation density would have the greatest impact on the discrepancy among the flux measurements when NEL was least representative of the field. To account for this, the adjustment to $\lambda E$ was scaled in proportion to the difference in LAI within NEL and the surrounding field while maintaining a mean adjustment of $60 \mathrm{~W} \mathrm{~m}^{-2}$. With this adjustment, the portion of the daytime $\mathrm{MD}_{1, \mathrm{~N}}$ that remains to be explained is $41 \mathrm{~W} \mathrm{~m}^{-2}$ while the portion of the daytime $\mathrm{MD}_{8, \mathrm{~N}}$ that remains to be explained is $43 \mathrm{~W} \mathrm{~m}{ }^{-2}$. While there were differences in the vegetation within SEL and the remainder of SEF as well, the analysis by Evett et al. [85] could not link it to differences in $\lambda E$ in that field. Therefore, no similar adjustment was conducted for SEF.

\subsection{Effect of local advection}

The irrigated cotton fields in BEAREX08 were surrounded by bare, dryland crop and grassland fields. Consequently, the juxtaposition of relatively cool, moist cotton fields with the surrounding dry fields resulted in the development of local advective conditions, particularly later in the study period when the cotton was well developed. Using a combination of Micronet, EC, and LY-based measurements, the influence of advection on the discrepancy in the flux measurements was characterized.

Although the effect of advection was typically less than $20 \mathrm{~W}$ $\mathrm{m}^{-2}$, there were a small number of days later in the season when the effect was significantly greater (Fig. 16). For two days in particular - 31 July (DOY 213) and 6 August (DOY 219) - the advective contribution was $100 \mathrm{~W} \mathrm{~m}^{-2}$ or more. The Fig. also shows that $\lambda E_{\text {adv }}$ tended to increase over time as the cotton crop grew and 

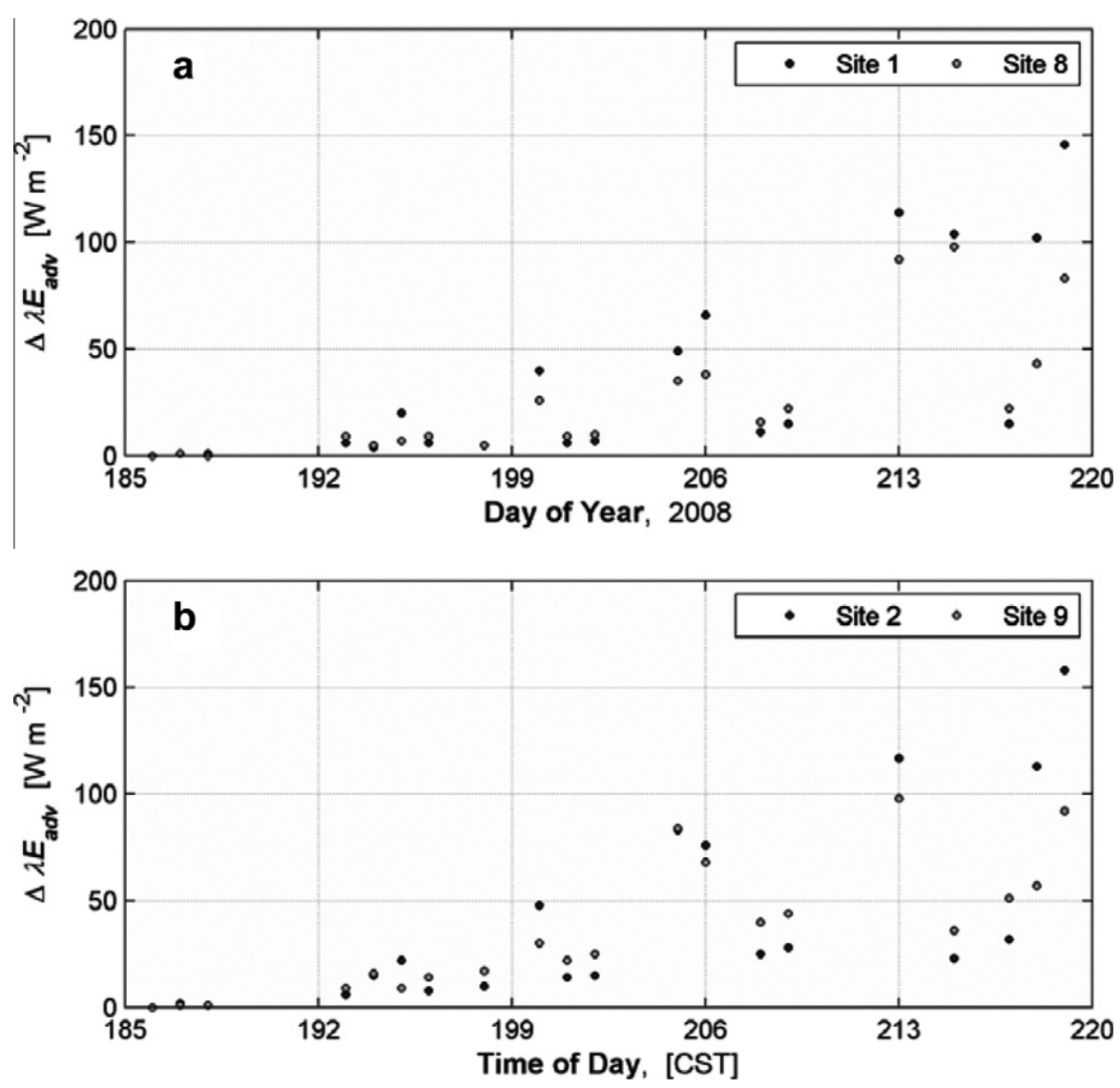

Fig. 16. The magnitude of the advective contribution to the turbulent fluxes is shown for the Northeast Field (a) and Southeast Field (b).
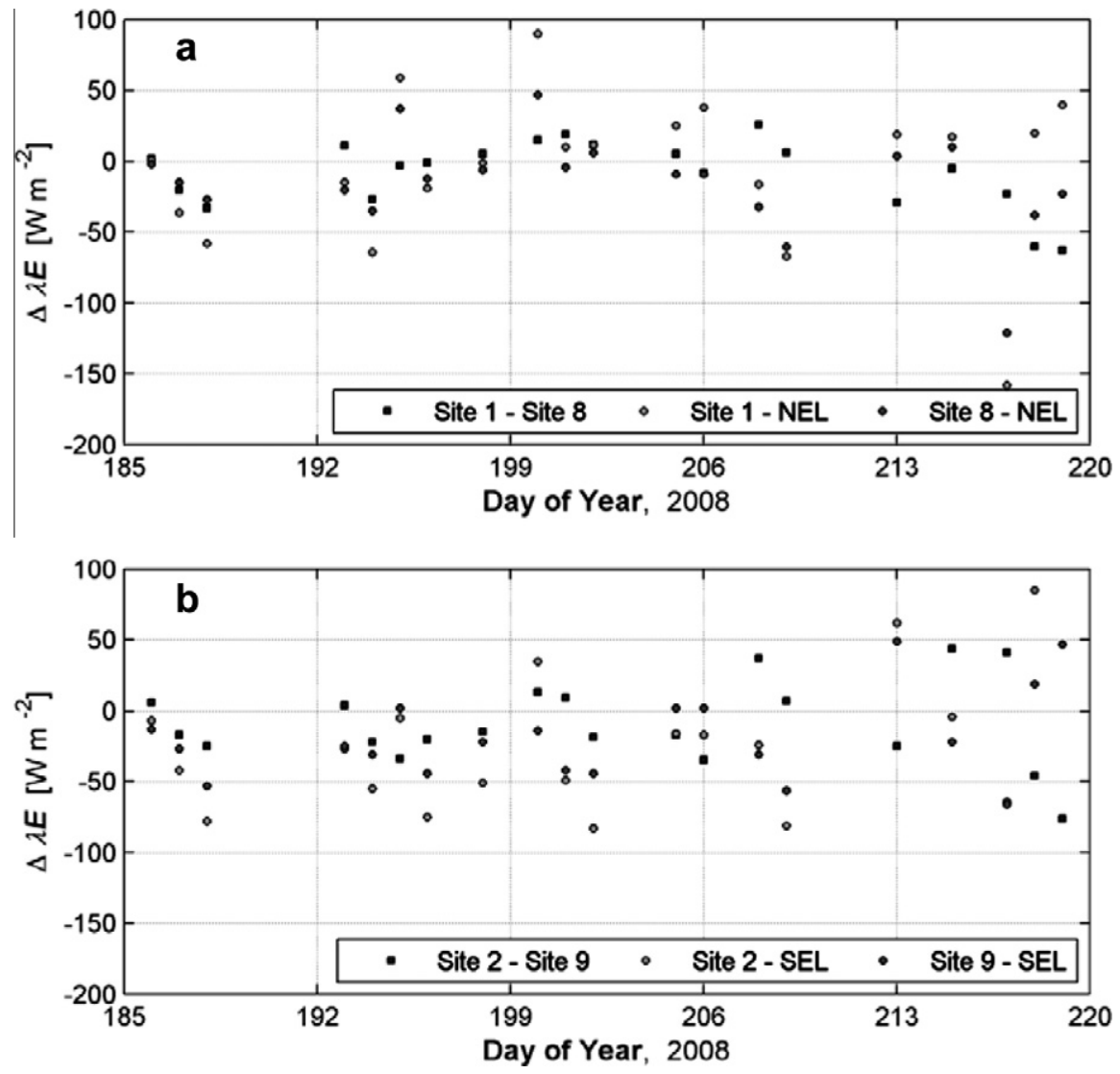

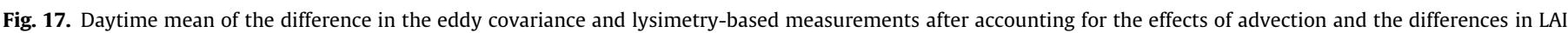


the vegetation became the dominant control on the surface characteristics in the two fields.

Overall, for $\lambda E$, the daytime $\mathrm{MD}_{1, \mathrm{~N}}$ and $\mathrm{MD}_{8, \mathrm{~N}}$ were $-6 \mathrm{~W} \mathrm{~m}^{-2}$ and $-16 \mathrm{~W} \mathrm{~m}^{-2}$, respectively, after accounting for the advective effect, as well as the effects of incomplete energy balance closure and differences in vegetation density. In SEF, $\mathrm{MD}_{2, S}$ was $-20 \mathrm{~W} \mathrm{~m}^{-2}$ while $\mathrm{MD}_{9, \mathrm{~S}}$ was $-19 \mathrm{~W} \mathrm{~m}^{-2}$. Although there was no apparent temporal pattern in the discrepancy between the EC and LY-based measurements after accounting for differences in LAI and advection (Fig. 17), there was a fair amount of variability in MD values on a day-to-day basis. The standard deviations of the discrepancies ranged between approximately $30 \mathrm{~W} \mathrm{~m}^{-2}$ and $50 \mathrm{~W} \mathrm{~m}^{-2}$. This spread is likely due to the imperfect estimates of both the vegetation density and advective effects. The remaining differences are likely due to the uncertainty associated with the EC and LY-based measurements caused by factors not considered in this study. For example, a recent study by Kochendorfer et al. [84] showed that the design of many sonic anemometers, including the type used in this study, can cause systematic underestimates of the vertical wind velocity, and thus, the turbulent fluxes.

\section{Conclusions}

The results of this analysis suggest that variations in surface conditions can introduce uncertainty into both eddy covariance and lysimetry-based flux measurements. Moreover, the induced uncertainty can result in substantially different measurements of the turbulent fluxes. In this study there were three factors that contributed to the discrepancy among the flux measurements. Two of these factors, namely the imperfect closure of the energy balance and the effects of strong local advection, were associated with the EC systems. The third factor, differences in the vegetation density as measured by LAI between the measurement source area and the field as a whole, resulted in a greater moisture flux from within the lysimeter in the NEF. For comparison, approximately $34 \%$ of the discrepancy between the measurements of $\lambda E$ in NEF can be attributed to imperfect closure, $36 \%$ can be attributed to differences in vegetation density, $22 \%$ can be attributed to advective effects, and the remaining $8 \%$ is linked to measurement uncertainty. By accounting for these differences, the measurements made by the two techniques can be largely reconciled.

Moreover, by showing that neither measurement method is immune to the effects of a heterogeneous surface on land-atmosphere exchange, the results of this study have important implications for the scientific and larger communities. As was noted earlier, accurate estimates of both the current and future water needs of crops are needed in order to maximize the efficient use of water for irrigation and agricultural activities. The development of remote sensing-based and other monitoring and modeling schemes, along with investigations into the fundamental processes controlling the exchange of heat moisture between the surface and the atmosphere, relies on in situ measurements of surface fluxes. Flux measurements are used to parameterize, calibrate, and validate these models. As such, the uncertainty associated with flux measurements will impact the results of both those research activities and the operational output of the models. This study highlights the uncertainties that can occur with both eddy covariance and lysimetry and underscores the need to fully understand the limitations of in situ measurements and their impact on subsequent research activities. This is particularly poignant now. As the demand for fresh water continues to grow, the need for accurate data describing current and future surface moisture fluxes and water needs to inform the decisions of policy makers, water resource managers, and members of the agricultural community will also grow. Fulfilling this need requires that the limitations and uncertainties of observational methods be fully understood.

\section{Acknowledgements}

This project would not have been possible without the cooperation and assistance of the scientists and staff at the USDA, ARS, Conservation and Production Research Laboratory, Soil and Water Management Research Unit. The authors would also like to thank the reviewers for their helpful comments that greatly enhanced the quality and clarity of the manuscript.

\section{References}

[1] Jenerette GD, Marussich WA, Newell JP. Linking ecological footprints with ecosystem valuation in the provisioning of urban freshwater. Ecol Econ 2006;59(38):47.

[2] Calzadill A, Rehdanz K, Tol RSJ. The economic impact of more sustainable water use in agriculture: a computable general equilibrium analysis. J Hydrol 2010;384:292-305

[3] Wada Y, van Beek LPH, van Kempen CM, Reckman JWTM, Vasak S, Bierkens MFP. Global depletion of groundwater resources. Geophys Res Lett 2010:37. http://dx.doi.org/10.1029/1029/2010GL04457.

[4] Vörösmarty CJ, Green P, Salisbury J, Lammers RB. Global water resources: vulnerability from climate change and population growth. Science 2000;289:284-8.

[5] Zehnder AJB, Yang H, Schertenleib R. Water issues: the need for action at different levels. Aquatic Sci 2003;65:1-20.

[6] Qadir M, Boers TM, Schubert S, Ghafoor A, Murtaza G. Agricultural water management in water-starved countries: challenges and opportunities. Agric Water Manag 2003;62:165-85.

[7] Hanasaki N, Kanae S, Oki T, Masuda K, Motoya K, Shirakawa N, Shen Y, Tanaka $K$. An integrated model for the assessment of global water resources. Part 2: Applications and assessments. Hydrol Earth System Sci 2008;12:1027-37.

[8] Scanlon BR, Reedy RC, Gates JB, Gowda PH. Impacts of agroecosytems on groundwater resources in the Central High Plains, USA. Agric Ecosys Environ 2010;139:700-13.

[9] Oweis TY, Farahani HJ, Hachum AY. Evapotranspiration and water use of full and deficit irrigated cotton in the Mediterranean environment in northern Syria. Agric Water Manag 2011;98:1239-48.

[10] Wallace JS. Increasing agricultural water use efficiency to meet future food production. Agric Ecosyst Environ 2000;82:105-19.

[11] Green GP, Hamilton JR. Water allocation, transfers, and conservation: links between policy and hydrology. Int J Water Resour Dev 2000;16:197-208.

[12] Sun G, McNulty SG, Moore Meyers JA, Cohen EC. Impacts of multiple stresses on water demand and supply across the southeastern United States. J Am Water Resour Assoc 2008;44:1441-57.

[13] Woodhouse CA, Lukas JJ. Multi-century tree-ring reconstructions of Colorado streamflow for water resource planning. Climatic Change 2006;78:293-315.

[14] Watson PS, Davies S. Modelling the effects of population growth on water resources: a CGE analysis of the South Platte River Basin in Colorado. Ann Reg Sci 2011;46:331-48.

[15] Koniecki AD, Heilman JA. Water-use trends in the desert Southwest-19502000: US Geological Survey Scientific Investigations, Report 2004-5148; 2004. p. 32.

[16] Hunsaker DJ, French AN, Clarke TR, El-Shikha DM. Water use, crop coefficients, and irrigation management criteria for camelina production in arid regions. Irrig Sci 2011;29:27-43.

[17] Sophocleous M. Groundwater recharge and sustainability in the high plains aquifer in Kansas, USA. Hydrogeol J 2005;13:351-65.

[18] Frederick KD, Schwarz GE. Socioeconomic impacts of climate change on US water supplies. J Am Water Resour Assoc 1999;35:1563-83.

[19] Berrittella M, Hoekstra AY, Rehdanz K, Roson R, Tol RSJ. The economic impact of restricted water supply: a computable general equilibrium analysis. Water Res 2007; 41:1799-813.

[20] de Fraiture C, Wichelns D. Satisfying future water demands for agriculture. Agic Water Manag 2010;97:502-11.

[21] Shiklomanov IA. Appraisal and assessment of world water resources. Water Int 2000;25:11-32.

[22] Gordon LJ, Finlayson CM, Falkenmark M. Managing water in agriculture for food production and other ecosystem services. Agric Water Manag 2010;97:512-9.

[23] Howell TA. Enhancing water use efficiency in irrigated agriculture. Agron J 2001;93:281-9.

[24] Schultz B, De Wrachien D. Irrigation and drainage systems research and development in the 21st century. Irrig Drain 2002;51:311-27.

[25] Scanlon BR, Jolly I, Sophocleous M, Zhang L. Global impacts of conversions from natural to agricultural ecosystems on water resources: quantity versus quality. Water Resour Res 2007:43. http://dx.doi.org/10.1029/2006WR00548.

[26] Turral H, Svendsen M, Faures JM. Investing in irrigation: reviewing the past and looking to the future. Agric Water Manag 2010;97:551-60. 
[27] Kenny JF, Barber NL, Hutson SS, Linsey KS, Lovelace JK, Maupin MA. Estimated use of water in the United States in 2005. US Geological Survey Circular 1344; 2009. p. 52.

[28] Agam N, Kustas WP, Anderson MC, Li F, Colaizzi PD. Utility of thermal image sharpening for monitoring field-scale evapotranspiration over rainfed and irrigated agricultural regions. Geophys Res Lett 2008;35. http://dx.doi.org/ $10.1029 / 2007$ GL032195.

[29] Abdelghani C, Hoedjes JCB, Rodriquez J-C, Watts CJ, Garatuza J, Frederic J, et al. Using remotely sensed data to estimate area-averaged daily surface fluxes over a semi-arid mixed agricultural land. Agric For Meteorol 2008; $148: 330-42$.

[30] Famiglietti JS, Lo M, Ho SL, Bethune J, Anderson KA, Syed TH, Swenson SC, de Linage CR, Rodell M. Satellites measure recent rates of groundwater depletion in California's Central Valley. Geophys Res Lett 2011;38. http://dx.doi.org/ 10.1029/2010GL046442.

[31] Allen RJ, Pereira LS, Howell TA, Jensen ME. Evapotranspiration information reporting: I. Factors governing measurement accuracy. Agric Water Manag 2011;98:899-920.

[32] Goring DG, Nikora VI. Despiking acoustic doppler velocimeter data. J Hydrol Eng 2002;128:117-26.

[33] Tanner CB, Thurtell, G. Anemoclinometer measurements of Reynolds stress and heat transport in the atmospheric surface layer. Research and Development Technical Report to US Army Electronic Command, ECOM 66G22-F. Department of Soil Sciences, University of Wisconsin; 1969. P. 199.

[34] Kaimal JC, Finnigan JJ. Atmospheric boundary layer flows. New York: Oxford University Press; 1994. p. 289.

[35] Massman WJ. A simple method for estimating frequency response corrections for eddy covariance systems. Agri For Meteorol 2000;104:185-98.

[36] Massman WJ, Lee X. Eddy covariance flux corrections and uncertainties in long term studies of carbon and energy exchanges. Agri For Meteorol 2002;113:121-44.

[37] Webb EK, Pearman GL, Leuning R. Correction of flux measurements for density effects due to heat and water vapour transfer. Q J Roy Meteorol Soc 1980;106:85-100.

[38] Leuning R. Measurements of trace gas fluxes in the atmosphere using eddy covariance. WPL corrections revisited. In: Lee X, Massman W, Law B, editors. Handbook of micrometeorology: a guide for surface flux measurement and analysis. Boston: Kluwer Academic Publisher; 2004.

[39] Liu H, Peters G, Foken T. New equations for sonic temperature variance and buoyancy heat flux with an omnidirectional sonic anemometer. BoundaryLayer Meteorol 2001;100:459-68.

[40] Alfieri JG, Kustas WP, Prueger JH, Hipps LE, Chavez JL, French AN, et al. Intercomparison of nine micrometeorological stations during the BEAREX08 field campaign. J Atmos Ocean Technol 2011;28:1390-406.

[41] Kohsiek W, Liebethal C, Foken T, Vogt R, Oncley SP, Bernhofer C, De Bruin HAR. The energy balance experiment EBEX-2000. Part III: Behaviour and quality of the radiation measurements. Boundary-Layer Meteorol 2007;123:55-75.

[42] Michel D, Philipona R, Ruckstuhl C, Vogt R, Vuilleumier L. Performance and uncertainty of CNR1 net radiometers during a one-year field comparison. J Atmos Oceanic Technol 2008;25:442-51.

[43] Blonquist JM, Tanner BD, Bugbee B. Evaluation of measurement accuracy and comparison of two new and three traditional net radiometers. Agric For Meteorol 2009;149:1709-21.

[44] Marek TH, Schneider AD, Howell TA, Ebeling L. Design and construction of large weighing monolithic lysimeters. Trans ASAE 1988;31:477-84

[45] Howell TA, Schneider AD, Dusek DA, Marek TH, Steiner JL. Calibration and scale performance of Bushland weighing lysimeters. Trans ASAE 1995;38:1019-24.

[46] Evett SR, Schwartz RC, Tolk JA, Howell TA. Soil profile water content determination: spatio-temporal variability of electromagnetic and neutron probe sensors in access tubes. Vadose Zone J 2009;8:926-41.

[47] Chavez JL, Neale CMU, Hipps LE, Prueger JH, Kustas WP. Comparing aircraftbased remotely sensed energy balance fluxes with eddy covariance tower data using heat flux source area functions. J Hydrometeorol 2005;6:923-40.

[48] Chavez JL, Gowda PH, Howell TA, Neale CMU, Copeland KS. Estimating hourly crop ET using a two-source energy balance model and multispectral airborne imagery. Irrig Sci 2009;28:79-81.

[49] Basara JB, Illston BG, Winning TE, Fiebrich CA. Evaluation of rainfall measurements from the WXT510 sensor for use in the Oklahoma City micronet. Open Atmos Sci J 2009;3:39-47.

[50] Basara JB, Illston BG, Fiebrich CA, Browder PD, Morgan CR, McCombs A, Bostic JP, McPherson RA, Schroeder AJ, Crawford KC. The Oklahoma City micronet. Meteorol Appl 2010. http://dx.doi.org/10.1002/rmet.189.

[51] Alfieri JG, Niyogi D, Zhang H, LeMone MA, Chen F. Quantifying the spatial variability of surface fluxes using data from the 2002 International H2O Project. Boundary-Layer Meteorol 2009;133:323-41.

[52] Schabenberger O, Gotway CA. Statistical methods for spatial data analysis. New York: Chapman \& Hall; 2005. 516 p.

[53] Isaaks EH, Srivastava RM. Applied geostatistics. New York: Cambridge University Press; 1989. 561 p.

[54] Pasquill F, Smith FB. Atmospheric diffusion. NewYork: John Wiley \& Sons; 1983. $427 \mathrm{p}$.

[55] Finnigan JJ. The footprint concept in complex terrain. Agric For Meteorol 2004;127:117-29.

[56] Schmid HP. Footprint modelling for vegetation atmosphere exchange studies: a review and perspective. Agric For Meteorol 2002;113:159-83.
[57] Hsieh C-I, Katul G, Chi T-W. An approximate analytical model for footprint estimation of scalar fluxes in thermally stratified atmospheric flows. Adv Water Res 2000;23:765-72.

[58] Horst TW, Weil JC. Footprint estimation for scalar flux measurements in the atmospheric surface layer. Boundary-Layer Meteor 1992;59:279-96.

[59] Horst TW, Weil JC. How far is far enough? The fetch requirements for micrometeorological measurement of surface fluxes. J Atmos Oceanic Technol 1994;11:1018-25.

[60] Brakke TW, Verma SB, Rosenberg NJ. Local and regional components of sensible heat advection. J Appl Meteorol 1978;17:955-63.

[61] Prueger JH, Hipps LE, Cooper DI. Evaporation and the development of the local boundary layer over an irrigated surface in an arid region. Agric For Meteorol 1996;78:223-37.

[62] Figuerola PI, Berliner PR. Evaporation under advective conditions. Int J Biometeorol 2005;49:403-16.

[63] Hanks RJ, Allen LH, Gardner HR. Advection and evapotranspiration of widerow sorghum in the Central Great Plans. Agron J 1971;63:520-7.

[64] Verma SB, Rosenberg J, Blad BL. Turbulent exchange coefficients for sensible heat and water vapor under advective conditions. J Appl Meteorol 1978:330-8.

[65] McAneney KJ, Brunet Y, Itier B. Downwind evolution of transpiration by two irrigated crops under conditions of local advection. J Hydrol 1994;161:375-88.

[66] Zermeno-Gonzalez A. Hipps LE. Downwind evolution of surface fluxes over vegetated surface during local advection of heat and saturation deficit. J Hydrol 1997; 192:189-210.

[67] Li L, Yu Q. Quantifying the effects of advection on canopy energy budgets and water use efficiency in an irrigated wheat field in the North China Plain. Agric Water Manag 2007;89:116-22.

[68] Stull RB. Introduction to boundary layer meteorology. Dordrecht: Kluwer Academic Publishers; 1988. p. 668

[69] Philip JR. The theory of local advection. J Meteorol 1959;16:535-47.

[70] Itier B, Brunet Y, McAnerney KJ, Lagouarde JP. Downwind evolution of scalar fluxes and surface resistance under conditions of local advection. Part 1: A reappraisal of boundary conditions. Agric For Meteorol 1994;71:211-25.

[71] Kochendorfer J, Paw UK. Field estimates of scalar advection across a canopy edge. Agric For Meteorol 2011;151:585-94.

[72] Kustas WP, Prueger JH, Hatfield JL, Ramalingam K, Hipps LE. Variability in soil heat flux from a mesquite dune site. Agric For Meteorol 2000; 103:249-64.

[73] Shao C, Chen J, Li L, Xu W, Chen S, Gwen T, Xu J, Zhang W. Spatial variability in soil heat flux at three Inner Mongolia steppe ecosystems. Agric For Meteorol 2008;148:1433-43.

[74] Finnigan JJ, Clement R, Malhi Y, Leuning R, Cleugh HA. Re-evaluation of longterm flux measurement techniques. Part I: Averaging and coordinate rotation. Boundary-Layer Meteorol 2003;107:1-48.

[75] Oncley SP, Foken T, Vogt R, Kohsiek W, DeBruin HAR, Bernhofer C, Christen A van Gorsel E, Grantz D, Feignwinter C, Lehner I, Liebethal C, Liu H, Mauder M, Pitacco A, Ribeiro L, Weidinger T. The energy balance experiment EBEX-2000. Part I: Overview and energy balance. Boundary-Layer Meteorol 2007;123:1-28.

[76] Foken T. The energy balance closure problem. An overview. Ecol Appl 2008; 18:1351-67.

[77] Blanken PD, Black TA, Yang PC, Neumann HH, Nesic Z, Straebler R, den Hartog G, Novak MD, Lee X. Energy Balance and canopy conductance of a boreal aspen forest: Partitioning overstory and understory components. J Geophys Res 1997;102:28915-27.

[78] Twine TE, Kustas WP, Norman JM, Cook DR, Houser PR, Meyers TP, Prueger JH Starks PJ, Wesely ML. Correcting eddy-covariance flux underestimates over a grassland. Agric For Meteorol 2000;103:279-300.

[79] Prueger JH, Hatfield JL, Kustas WP, Hipps LE, MacPherson JI, Parkin TB. Tower and aircraft eddy covariance measurements of water vapor, energy and carbon dioxide fluxes during SMACEX. J Hydrometeor 2005;6:954-60.

[80] Guillevic P, Koster RD, Suarez MJ, Bounoua L, Collatz GJ, Los OS Mahanama SPP. Influence of the interannual variability of vegetation on the surface energy balance-a global sensitivity study. J Hydrometeorol 2002;3:617-29.

[81] Scanlon TM, Albertson JD. Water availability and the spatial complexity of $\mathrm{CO}_{2}$ water, and energy fluxes over a heterogeneous sparse canopy. J Hydrometeorol 2003;4:798-809.

[82] Kalma JD, McVicar TR, McCabe MF. Estimating land surface evaporation: a review of methods using remotely sensed surface temperature data. Surv Geophys 2008;29:421-69.

[83] Alfieri JG, Blanken PD. How representative is a point? The spatial variability of surface energy fluxes across short distances in a sand-sagebrush ecosystem. Arid Environ; in press.

[84] Kochendorfer J, Meyers TP, Frank J, Massman WJ, Heuer MW. How well can we measure the vertical wind speed? Implications for fluxes of energy and mass. Bound-Layer Meteorol; in press.

[85] Evett ER, Kustas WP, Gowda PH, Anderson MC, Prueger JH, Howell TA Overview of the Bushland evapotranspiration and agricultural remote sensing experiment 2008 (BEAREX08): a field experiment evaluating methods for quantifying ET at multiple scales. Adv Water Resour 2012;50:4-19.

[86] Agam N, Evett SR, Tolk JA, Copeland KS, Howell TA, Colaizzi PD, Kustas WP. Evaporative loss from irrigated interrows in a highly advective semi-arid agricultural area. Adv Water Resour 2012;50:20-30. 